\title{
Development of a Novel Simplified PBPK Absorption Model to Explain the Higher Relative Bioavailability of the OROS® Formulation of Oxybutynin
}

\author{
Andrés Olivares-Morales, ${ }^{1,2,5}$ (i) Avijit Ghosh, ${ }^{3}$ Leon Aarons, ${ }^{1}$ and Amin Rostami-Hodjegan ${ }^{1,4}$
}

Received 27 April 2016; accepted 21 July 2016; published online 8 September 2016

\begin{abstract}
A new minimal Segmented Transit and Absorption model (mSAT) model has been recently proposed and combined with intrinsic intestinal effective permeability $\left(P_{\text {eff,int }}\right)$ to predict the regional gastrointestinal (GI) absorption $\left(f_{a b s}\right)$ of several drugs. Herein, this model was extended and applied for the prediction of oral bioavailability and pharmacokinetics of oxybutynin and its enantiomers to provide a mechanistic explanation of the higher relative bioavailability observed for oxybutynin's modified-release OROS ${ }^{\circledR}$ formulation compared to its immediate-release (IR) counterpart. The expansion of the model involved the incorporation of mechanistic equations for the prediction of release, transit, dissolution, permeation and first-pass metabolism. The predicted pharmacokinetics of oxybutynin enantiomers after oral administration for both the IR and OROS ${ }^{\circledR}$ formulations were in close agreement with the observed data. The predicted absolute bioavailability for the IR formulation was within $5 \%$ of the observed value, and the model adequately predicted the higher relative bioavailability observed for the OROS® formulation $v s$. the IR counterpart. From the model predictions, it can be noticed that the higher bioavailability observed for the OROS $®$ formulation was mainly attributable to differences in the intestinal availability $\left(F_{G}\right)$ rather than due to a higher colonic $f_{a b s}$, thus confirming previous hypotheses. The predicted $f_{a b s}$ was almost $70 \%$ lower for the OROS ${ }^{\circledR}$ formulation compared to the IR formulation, whereas the $F_{G}$ was almost eightfold higher than in the IR formulation. These results provide further support to the hypothesis of an increased $F_{G}$ as the main factor responsible for the higher bioavailability of oxybutynin's OROS ${ }^{\circ}$ formulation $v s$. the IR.
\end{abstract}

KEY WORDS: CYP3A; formulation; intestinal metabolism; OROS®; oxybutynin; PBPK model.

\section{INTRODUCTION}

In recent years, there has been an increase in the use of physiologically based pharmacokinetics (PBPK) models in drug development, particularly in the pre-clinical and early clinical stages. Numerous articles coming from academia,

Electronic supplementary material The online version of this article (doi:10.1208/s12248-016-9965-3) contains supplementary material, which is available to authorized users.

${ }^{1}$ Centre for Applied Pharmacokinetic Research, Manchester Pharmacy School, The University of Manchester, Manchester, UK.

${ }^{2}$ Present Address: Roche Pharma Research and Early Development (pRED), Roche Innovation Center Basel. F. Hoffmann-La Roche Ltd, Grenzacherstrasse 124, 4070, Basel, Switzerland.

${ }^{3}$ Janssen Pharmaceutica, Spring House, Pennsylvania, USA.

${ }^{4}$ Certara, Sheffield, UK.

${ }^{5}$ To whom correspondence should be addressed. (e-mail: andres.olivares@roche.com)

ABBREVIATIONS ACAT, Advanced Compartmental Absorption and Transit; ADAM, Advanced Dissolution Absorption and Metabolism; AGP, $\alpha_{1}$-Acidglycoprotein; AUC, Area under the curve; BCS, Biopharmaceutical Classification System; BW, Body weight; CES1, industry and regulatory agencies have highlighted the benefits of applying such models in the drug discovery and development arena (1-6). By incorporating some of the mechanisms driving the pharmacokinetics of a drug, PBPK models allows one to distinguish between drug-related and the physiological factors controlling drug absorption, distribution, metabolism

Carboxylesterase 2; $C_{\max }$, Maximum plasma/blood concentration; $\mathrm{CO}$, Cardiac output; CPGA, 2-Cyclohexyl-2-phenylglycolic acid; CR, Controlled release; DEOB, $N$-Desethyloxybutynin; $F$, Absolute oral bioavailability; $\mathrm{f}_{a b s}$, Fraction of the dose absorbed in the gastrointestinal tract; $\mathrm{F}_{G}$, Fraction of the dose absorbed that escapes gut wall firstpass metabolism; $F_{H}$ Fraction of the dose absorbed that escapes hepatic first-pass metabolism; FOCE-I, First-order conditional with interaction maximum likelihood estimation method; $F_{\text {rel }}$ Relative bioavailability; GI, Gastrointestinal; HLM, Human liver microsomes; IR, Immediate release; $I V$ or $i v$, Intravenous; LC-MS/MS, Liquid chromatography with tandem mass spectrometry detection; $\mathrm{M} \& \mathrm{~S}$, Modelling and simulation; MR, Modified release; mSAT, Minimal segmented absorption and transit; OrBiTo, Oral biopharmaceutics tools; OROS, Osmotic controlled-release oral delivery system; OXY, Oxybutynin; PBPK, Physiologically based pharmacokinetic(s); $P_{\text {eff }}$, intestinal effective permeability; SI, Small intestine (al); SITT, Small intestinal transit time 
and elimination (ADME). This characteristic enables one to integrate measured in vitro or in silico drug properties into the model in the so-called in vitro-in vivo extrapolation (IVIVE) approach, enabling the use of such models in a truly prospective fashion (6). PBPK models have been increasingly applied in oral absorption and biopharmaceutics. This has been partly due to the development and availability of mechanistic absorption models such as the ones included in commercial software packages like SimCYP® (ADAM) (7), GastroPlus $^{\mathrm{TM}}$ (ACAT) (8) and PK-Sim ${ }^{\circledR}(9,10)$, as well as some in-house developments coming from academia and industry (11-14).

Oral absorption and bioavailability are dependent upon numerous physiological and drug-related factors interacting simultaneously. These factors are the key to defining the different steps of the oral absorption process, i.e. transit, dissolution, release, permeation, transport and metabolism $(15,16)$. Given the complex nature of these drug-physiology interactions, prospective predictions of oral bioavailability within the PBPK framework are still a challenging task (1719). Nevertheless, significant efforts have recently been made in order to improve our understanding of such a complex interplay. For instance, the Innovative Medicines Initiative (IMI) OrBiTo project has amongst its goals to enrich our knowledge of the physiological and biopharmaceutical properties that define in vivo drug absorption and to provide new in vitro and in silico tools that can help to make better predictions of the in vivo drug product performance (20).

One of the key biopharmaceutical factors defining oral drug absorption are formulation characteristics. In a recent study, we investigated the impact that modified/controlled release (MR/ $\mathrm{CR}$ ) formulations might have on the oral bioavailability of substrates of the cytochrome P450 (CYP) 3A4 enzymes using a prospective PBPK modelling and simulation (M\&S) approach (21). By employing this approach, we were able to evaluate the interplay between drug and physiological-related factors governing intestinal absorption and first-pass metabolism, and in particular to identify the possible scenarios where MR formulations of a CYP3A substrate might display higher relative bioavailability $\left(F_{\text {rel }}\right)$ compared to its immediate released (IR) counterparts (21). In our previous study, it was shown that highly cleared CYP3A-substrates belonging to Class 1 within the biopharmaceutics classification system (BCS) are more likely to display higher $F_{r e l}$ when formulated as MR (21). The mechanism proposed for this phenomenon is an increased intestinal availability $\left(F_{G}\right)$ due to a decreased intestinal first-pass metabolism as a result of the lower abundance of CYP3A enzymes in the distal gastrointestinal (GI) tract, where most of the drug contained in the MR formulation is likely to be released and absorbed (21-24). Another interesting outcome of the study was the observed trend to over predict $f_{a b s}$ of MR formulations belonging to BCS Classes 2 and $3(21,25)$. This over prediction was attributed to an overestimation of the colonic absorption due to the PBPK approach employed for the study. That is, intestinal effective permeability $\left(P_{\text {eff }}\right)$ was assumed to be same for all intestinal segments implemented in the absorption model, including the colon (21). In an attempt to address this issue, and given the lack of an implementation of regional intestinal (passive) permeability within in the PBPK framework, two novel approaches to implement regional $P_{\text {eff }}$ for prospective PBPK simulations were recently proposed (26). The approaches were based on the translation of regional intestinal variations in the available mucosal surface area (mSA) into segment-dependent permeability and absorption (26). When the approaches were combined with a novel simplified absorption PBPK model, or minimal Segmented Absorption and Transit (mSAT) model, they showed a potential to decrease the observed overestimation of the colonic $f_{a b s}(26)$, especially when applying the so-called Method 3 (M3) which was based on the intestinal mSA values derived recently by Helander and Fändriks (26,27).

One of the limitations of the prospective PBPK analysis of the bioavailability differences between IR and MR formulations of CYP3A substrates was the lack of drug-specific simulations necessary to provide stronger support for the prospective modelling and simulation study outcome (21). Therefore, the present work was designed as a continuation of the work performed in the previous studies, with the main aim to provide a drug-specific example to support the hypothesis of a reduced first-pass metabolism as the main driving mechanism of the higher $F_{r e l}$ of CYP3A substrates formulated as MR (21).

In particular, this study investigated the bioavailability differences observed for the MR formulation of oxybutynin (OXY). OXY is a highly cleared antimuscarinic drug with anticholinergic, spasmolytic and local anaesthetic properties employed for the treatment of urge urinary incontinency due to over activity of the detrusor muscle (28). OXY is a highly permeable and soluble compound (BCS Class 1) (21). After oral administration, OXY is rapidly absorbed and undergoes extensive first-pass metabolism in both the intestinal wall and the liver, mainly mediated by CYP3A4 (28-30). When formulated as a once a day (MR) OROS ${ }^{\circ}$ formulation, the relative bioavailability of OXY was around $153 \%$ compared to its IR tablet, while the exposure of its main metabolite, $\mathrm{N}$ desethyloxybutynin (DEOB) was reduced by almost 30\% (28). This reduction in exposure was translated into an improved safety profile due to a reduction in the incidence of dry mouth episodes, OXY's main side-effect, which is mainly attributed to its active metabolite, yet keeping the same efficacy (31,32).

In this study, OXY's bioavailability differences were investigated by means of a PBPK modelling and simulation approach, combining in vivo, in vitro and in silico data together with an extended version of the previously developed mSAT model. The model was expanded to prospectively predict OXY's oral bioavailability for both IR and MR formulations (26).

\section{MATERIALS AND METHODS}

\section{PBPK Model Development}

The PBPK model employed for the mechanistic pharmacokinetic prediction of OXY was developed using a two-step approach. Firstly, a compound-specific semi-physiological PBPK model was developed and optimized with intravenous (IV) data to describe OXY's disposition. Secondly, the optimized OXY's disposition model was coupled with an extended version of the generic mSAT model to predict oral absorption and bioavailability using an in vitro-in vivo extrapolation (IVIVE) approach. The two-stage approach was chosen as it reduces the confounding issues that can arise when drug's disposition is not properly considered in the prediction of oral pharmacokinetics, thus providing better information about the predictive performance of the oral absorption model (mSAT). 
The details of the different steps of the model development are described in the following sections:

\section{Development of OXY's Disposition Model}

The semi-physiological PBPK model employed to describe OXY's disposition was developed based on the approach proposed by Cao and Jusko, whereby the model structure represents a hybrid between a whole-body PBPK model and a compartmental or mammillary pharmacokinetic model (33). The advantage of employing such an approach, compared to the use of traditional compartmental models, is that the former allows the use of prior physiological and anatomical knowledge to define the model structure. Therefore, under this approach, the model parameters are constrained between physiologically plausible limits (33). This approach appropriately distinguishes between drug-related and system-specific parameters, as the model can be informed from known drug-related properties, such as plasma protein binding and/or metabolic routes (33). It should be noted however that the model structure was not the product of the reduction of a whole-body PBPK model using formal reduction techniques such as "proper lumping" (34-36). In contrast, the model development was data driven, whereby the number of tissue compartments was defined based on the best description of the observed clinical data.

The selected structure of the disposition model is shown in Fig. 1a. The model is comprised of two anatomically defined compartments, systemic blood and liver, and three additional empirical tissue compartments, necessary to describe OXY's disposition after an intravenous (IV) infusion (30). All of the aforementioned compartments were assumed to be well-mixed, where drug transport into and from the tissues was assumed to occur by means of perfusion-limited processes.

The drug's concentration in the $i$ th non-eliminating empirical tissue was described by Eq. 1,

$V_{\text {tissue }, i} \times \frac{d C_{\text {tissue }, i}}{d t}=Q_{\text {tissue }, i} \times\left(C_{\text {blood }}-\frac{C_{\text {tissue }, i}}{K_{b, t i s s u e}}\right)$

where $V_{\text {tissue,i }}$ represents the tissue volume $(\mathrm{L}), C_{\text {tissue, }}$ is the drug's concentration in the tissue $(\mathrm{mg} / \mathrm{L}), Q_{\text {tissue, i }}$ is the tissue blood flow $(\mathrm{L} / \mathrm{h})$ and $K_{\mathrm{b} \text {,tissue }}$ is an empirical tissue to blood partition coefficient necessary to describe the extent of OXY's distribution into the tissue compartment. The dynamics in the blood compartment were described by Eq. 2,

$$
\begin{aligned}
V_{\text {blood }} \times \frac{d C_{\text {blood }}}{d t}= & R_{\text {in }}+\frac{1}{K_{b, \text { tissue }}} \\
& \times\left(\sum_{i=1}^{3} Q_{\text {tissue }, i_{i}} \times C_{\text {tissue }, i}\right) \\
& +Q_{H V} \times \frac{C_{\text {liver }}}{K_{\text {b,liver }}} \\
& -\left(\sum_{i=1}^{3} Q_{\text {tissue }_{i}}+Q_{\text {liver }}\right) \times C_{\text {blood }}
\end{aligned}
$$

where $V_{\text {blood }}$ is the systemic blood volume $(\mathrm{L}), R_{\text {in }}$ is the drug's infusion rate after IV administration $(\mathrm{mg} / \mathrm{h}), Q_{\mathrm{HV}}$ is the hepatic vein's blood flow, $C_{\text {liver }}$ is the concentration in the liver tissue, $K_{b \text {,liver }}$ is the drug's liver tissue to blood partition coefficient and $Q_{\text {liver }}$ is the combined hepatic and non-villous splanchnic blood flow (37-39). The latter parameter was defined the sum of the arterial blood supply to the liver and the non-villous portal blood flow (i.e. oesophagus, stomach, gut tissue, pancreas, upper large intestine, lower large intestine and spleen) (37-39). Given that the observed clinical data is usually reported as plasma concentrations rather than blood concentrations, the concentration represented by Eq. 2 (blood) was later expressed as plasma concentration by dividing $C_{\text {blood }}$ by the blood to plasma ratio (BP). OXY's systemic elimination was assumed to occur exclusively through hepatic metabolism, given that only less than $0.02 \%$ of the administered dose was found unchanged in the urine after IV administration (30). The dynamics of the liver compartment were described by Eq. 3,

$$
\begin{aligned}
V_{\text {liver }} \times \frac{d C_{\text {liver }}}{d t}= & \left(\sum_{n=1}^{4} Q_{\text {ent }, n} \times C_{\text {ent }, n}\right) \\
& +\left(Q_{\text {liver }} \times C_{\text {blood }}\right) \\
& -\left(Q_{H V}+f_{\text {up }} \times C L_{\text {liver }}\right) \times \frac{C_{\text {liver }}}{K_{b, \text { liver }}}
\end{aligned}
$$

where $Q_{\text {ent }, n}$ and $C_{\text {ent, } n}$ are the villous blood flow and concentration entering the liver from the $n$th enterocyte compartment, respectively (these values were assumed zero for IV administrations), $f_{u p}$ is the drug's fraction unbound in plasma and $\mathrm{CL}_{\text {liver }}$ is the OXY's hepatic clearance $(\mathrm{L} / \mathrm{h}) . \mathrm{CL}_{\text {liver }}$ was scaled from the drug's unbound intrinsic microsomal clearance $\left(\mathrm{CL}_{\mathrm{int}(\mathrm{u})}, \mathrm{L} / \mathrm{h} /\right.$ $\mathrm{mg}$ of microsomal protein) using the following equation (40)

$C L_{\text {liver }}=C L_{\text {int }(u)} \times L W \times M P P G L$

where $L W$ is the liver weight ( $\mathrm{g}$ ) and $M P P G L$ is the amount of microsomal protein per gram of liver $(\mathrm{mg} / \mathrm{g})$.

\section{Disposition Model Parameters and Parameter Estimation}

The majority of the system-related parameters employed in OXY's semi-physiological disposition model were derived from the literature and are summarized in Table I. The parameters were intended to represent those of a "reference individual", i.e. Caucasian male, $70 \mathrm{~kg}$ and $1.70 \mathrm{~m}$. The remaining model parameters were obtained by fitting the model shown in Fig. 1a to OXY's plasma concentration-time profile obtained after a $5 \mathrm{mg}$ IV infusion to four healthy volunteers published by Douchamps and co-workers (30). The data was digitized using GetData Graph Digitizer v2.26 (http://getdata-graphdigitizer.com/). The estimated parameters were $C L_{\text {int }(u)}$, $Q_{\text {tissue, },}, V_{\text {tissue,I }}$ (for tissues 1 to 3 ) and an empirical unbound tissue to plasma partition coefficient $\left(K_{\text {pu,tissue }}\right)$. $K_{p u}$ was assumed to be the same for all the empirical 


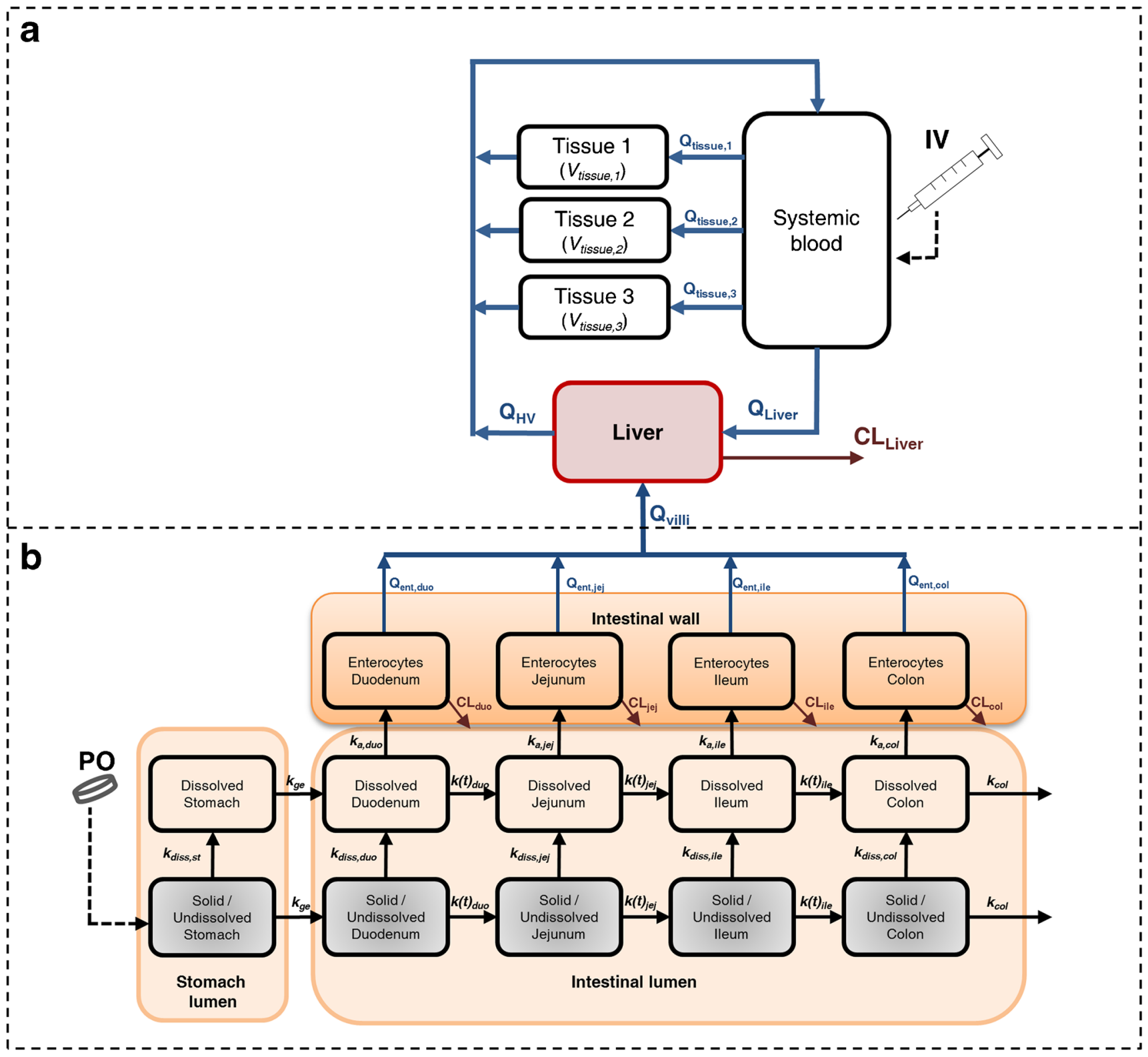

Fig. 1. Schematic representation of the PBPK model employed for OXY predictions. a Semi-physiological PBPK model employed to describe OXY's distribution. b Extended minimal segmented absorption and transit (mSAT) model for oral bioavailability predictions. $V_{\text {tissue }, i}$ volume of the $i$ th tissue, $Q_{\text {tissue, } i}$ blood flow entering and leaving the $i$ th tissue, $Q_{H V}$ hepatic vein blood flow, $Q_{\text {liver }}$ blood flow entering the liver, $C L_{\text {liver }}$ total liver clearance, $k_{G E}$ gastric emptying rate constant. For the $n$th intestinal segment: $k_{d i s s, n}$ dissolution rate constant, $k_{a, n}$ absorption rate constant, $C L_{n}$ intestinal clearance, $k_{t, n}$ transit rate (constant or time varying). More details with respect to the parameters can be found in the "Materials and Methods" section

tissues. The $K_{p u}$ was converted into a $K_{b}$ value, needed for the model equations, using the following equation (41),

$K_{b, i}=\frac{K_{p u, i} \times f_{u p}}{B P}$

where $B P$ is the OXY's blood to plasma ratio.

One of the main requisites for the disposition model was that the sum of the blood flows and tissue weights should be equal to the cardiac output (CO) and body weight (BW), respectively (33). To implement these constraints, $Q_{\text {tissue, } i}$ and $V_{\text {tissue, } i}$ were defined by Eqs. 6 and 7 , respectively,

$$
Q_{\text {tissue }, i}=f_{C O, i} \times\left(1-f_{C O, \text { liver }}\right) \times C O
$$

$V_{\text {tissue }, i}=\frac{f_{B W, i} \times\left(1-\left(f_{B W, \text { liver }}+f_{B W, \text { blood }}\right)\right) \times B W}{\rho_{\text {tissues }}}$

where $f_{c o, i}$ and $f_{B W, i}$ are the fractions of $\mathrm{CO}$ and $\mathrm{BW}$ for the $i$ th empirical tissue, respectively, $f_{C O \text {,liver }}$ is the fraction of the cardiac output corresponding to the blood flow entering the liver 
Table I. System-Related Parameters Used in the mSAT Model

\begin{tabular}{|c|c|c|c|c|c|}
\hline \multicolumn{2}{|l|}{ Parameter [units] } & \multicolumn{3}{|l|}{ Value } & Ref. $^{\text {a }}$ \\
\hline \multicolumn{2}{|l|}{ Reference body weight $(B W)[\mathrm{kg}]$} & \multicolumn{3}{|l|}{70} & S3 \\
\hline \multicolumn{2}{|l|}{ Reference height $(H T)[\mathrm{m}]$} & \multicolumn{3}{|l|}{1.70} & S3 \\
\hline \multicolumn{2}{|l|}{ Reference body surface area $(B S A)\left[\mathrm{m}^{2}\right]$} & \multicolumn{3}{|l|}{1.81} & $\mathrm{~S} 3$ \\
\hline \multicolumn{2}{|l|}{ Tissue density $\left(\rho_{\text {tissue }}\right)[\mathrm{kg} / \mathrm{L}]$} & \multicolumn{3}{|l|}{1.040} & $\mathrm{~S} 3$ \\
\hline \multicolumn{2}{|l|}{ Cardiac output (CO) [L/h] } & \multicolumn{3}{|l|}{350.37} & $\mathrm{~S} 3$ \\
\hline \multicolumn{2}{|l|}{ Blood weight $[\mathrm{kg}]$ (fraction of $B W$ ) } & \multicolumn{3}{|l|}{$5.53(0.079)$} & $\mathrm{S} 3$ \\
\hline \multicolumn{2}{|l|}{ Blood volume $\left(V_{\text {blood }}\right)[\mathrm{L}]$} & \multicolumn{3}{|l|}{5.32} & S3 \\
\hline \multicolumn{6}{|l|}{ Liver-specific parameters } \\
\hline \multicolumn{2}{|l|}{ Liver weight $[\mathrm{kg}]$ (fraction of $B W$ ) } & \multicolumn{3}{|l|}{$1.82(0.026)$} & $\mathrm{S} 3$ \\
\hline \multicolumn{2}{|l|}{ Liver density $\left(\rho_{\text {liver }}\right)[\mathrm{kg} / \mathrm{L}]$} & \multicolumn{3}{|l|}{1.080} & $\mathrm{~S} 3$ \\
\hline \multicolumn{2}{|l|}{ Liver volume $\left(V_{\text {liver }}\right)[\mathrm{L}]$} & \multicolumn{3}{|l|}{1.69} & S3 \\
\hline Liver blood flow $\left(Q_{\text {liver }}\right)[\mathrm{L} / \mathrm{h}]($ fraction of $C O)$ & & $68.32(0.195)$ & & & S3 \\
\hline Hepatic vein blood flow $\left(Q_{H V}\right)[\mathrm{L} / \mathrm{h}]($ fraction of $C O)$ & & $89.34(0.255)$ & & & S3 \\
\hline MPPGL $[\mathrm{mg} / \mathrm{g}]$ & & 40 & & & S3 \\
\hline CYP abundances $\left(A_{C Y P j(\text { liver }), n}\right)[\mathrm{pmol} / \mathrm{mg}]$ & & & & & S3 \\
\hline$A_{\mathrm{CYP} 3 \mathrm{~A} 4 \mathrm{liver}}$ & & 137 & & & $\mathrm{~S} 3$ \\
\hline$A_{\mathrm{CYP} 2 \mathrm{C} 9 \mathrm{liver}}$ & & 73 & & & S3 \\
\hline$A_{\mathrm{CYP} 2 \mathrm{C} 19 \mathrm{liver}}$ & & 14 & & & S3 \\
\hline$A_{\mathrm{CYP} 2 \mathrm{D} 6 \mathrm{liver}}$ & & 8 & & & $\mathrm{~S} 3$ \\
\hline GI tract parameters & & & & & \\
\hline Gastric emptying rate constant $\left(k_{G E}\right)\left[\mathrm{h}^{-1}\right]$ & & 4 & & & S3 \\
\hline Mean intestinal transit time $(S I T T)$ & & 3.32 & & & S3 \\
\hline Ascending colon transit rate constant $\left(k_{t, c o l}\right)\left[\mathrm{h}^{-1}\right]$ & & 0.098 & & & S3 \\
\hline Degrees of flatness coefficient $(D F)$ & & 1.7 & & & S3 \\
\hline Small intestinal length $(L S I)[\mathrm{cm}]$ & & 670.7 & & & S3 \\
\hline & & Segr & & & \\
\hline Regional intestinal parameters & DUO & JEJ & ILE & COL & \\
\hline Radius $\left(r_{n}\right)[\mathrm{cm}]$ & 2.37 & 1.75 & 1.5 & 2.42 & S3 \\
\hline Length $\left(L_{n}\right)[\mathrm{cm}]$ & 53.7 & 248.2 & 368.9 & 16.7 & S3 \\
\hline Fractional length $\left(f_{L S I, n}\right)$ & 0.08 & 0.37 & 0.55 & - & $\mathrm{S} 3$ \\
\hline Cylindrical volume $[\mathrm{mL}]$ & $9.47 \times 10^{2}$ & $2.39 \times 10^{3}$ & $2.61 \times 10^{3}$ & $3.07 \times 10^{2}$ & $\mathrm{~S} 3$ \\
\hline Mucosal surface area $\left(m S A_{n}\right)\left[\mathrm{cm}^{2}\right]$ & $7.50 \times 10^{4}$ & $5.19 \times 10^{5}$ & $3.86 \times 10^{5}$ & $1.62 \times 10^{3}$ & S3 \\
\hline Surface area scaling factor ratio $\left(S A E F_{n}\right)$ & 0.49 & 1.00 & 0.58 & 0.033 & S3 \\
\hline Enterocyte height $[\mu \mathrm{m}]$ & 32.2 & 32.2 & 32.2 & 35.1 & S3 \\
\hline Enterocyte compartment volume $\left(V_{e n t, n}\right)[\mathrm{L}]$ & 0.0262 & 0.119 & 0.079 & $8.9 \times 10^{-4}$ & S3 \\
\hline Enterocyte compartment blood flow $\left(Q_{\text {entn }}\right)[\mathrm{L} / \mathrm{h}]($ fraction of $\mathrm{CO})$ & $1.33(0.0038)$ & $6.24(0.0178)$ & $9.25(0.0264)$ & $4.20(0.012)$ & $\mathrm{S} 3$ \\
\hline Intestinal CYP abundances $\left(A_{\mathrm{CYPj}(\mathrm{ent}), \mathrm{n}}\right)[\mathrm{pmol}]$ & & & & & \\
\hline$A_{\text {CYP3A4ent,n }}$ & 9110 & 36,060 & 21,030 & 0 & $\mathrm{~S} 3$ \\
\hline$A_{\mathrm{CYP} 2 \mathrm{C} 9 \mathrm{ent}, \mathrm{n}}$ & 1770 & 7030 & 4100 & 0 & S3 \\
\hline$A_{\mathrm{CYP} 2 \mathrm{C} 19 \mathrm{ent}, \mathrm{n}}$ & 210 & 820 & 480 & 0 & S3 \\
\hline$A_{\text {CYP2D6ent,n }}$ & 110 & 440 & 240 & 0 & $\mathrm{~S} 3$ \\
\hline & & Segr & & & \\
\hline Regional mSAT luminal parameters & DUO & JEJ & ILE & $\mathrm{COL}$ & \\
\hline $\mathrm{pH}$ & 6.4 & 6.6 & 7.1 & 6.5 & $\mathrm{~S} 3$ \\
\hline Baseline water volume $\left(V_{\text {lum }, n}\right)[\mathrm{mL}]$ & 6 & 13 & 24 & 5 & S3 \\
\hline
\end{tabular}

${ }^{a}$ More details and references for the system-related parameters can be found in Sect. 3 of the Supplementary Material (Table S.3)

(Table I), $f_{B W, \text { liver }}$ and $f_{B W \text {,blood }}$ are the fractions of the BW corresponding to the weight of the liver and blood, respectively, and $\rho_{\text {tissues }}$ is the tissue density $(\mathrm{kg} / \mathrm{L})$. The aforementioned fractions were parameterized using a logistic-normal transformation as suggested by Tsamandouras and co-workers (42). An example of this parameterization is shown in Eq. 8,

$$
\begin{aligned}
& f_{1}=\frac{e^{\theta_{1}}}{e^{\theta_{1}}+e^{\theta_{2}}+1} \\
& f_{2}=\frac{e^{\theta_{2}}}{e^{\theta_{1}}+e^{\theta_{2}}+1} \\
& f_{3}=\frac{1}{e^{\theta_{1}}+e^{\theta_{2}}+1}
\end{aligned}
$$

where $\theta_{1}$ and $\theta_{2}$ are the parameters needed to be estimated (on the logistic scale). This approach not only constrains the individual fractions to be between 0 and 1 but also imposes the constraint that the sum of the fractions should be equal to 1 (42). The selected parameterization also contributed to the structural identifiability of the model, as the parameters needed to be estimated for the empirical tissues (fractions of volumes and blood flows) were also reduced from six to four. The assumption of a single unique $K_{p u}$ to describe the extent of tissue distribution in all the empirical tissues was also based on identifiability grounds, due to the fact that an independent $K_{p u}$ for each tissue could not be uniquely identified given the model structure $(43,44)$. The latter was corroborated by performing a model structural identifiability analysis prior to the 
parameter estimation procedure $(43,44)$. The analysis was done using the "IdentifiabilityAnalysis" package for Mathematica (Wolfram Research, Inc., Champaign, IL, USA) $(45,46)$, where the model was shown to be at least locally identifiable, i.e. there is a finite set of solutions leading to the same input/output relationship $(43,45,46)$. For details on the Identifiability Analysis procedure and the Mathematica Package, readers are referred to $(45,46)$. Finally, the model parameters were estimated in NONMEM version 7.3 (ICON Development Solutions, Hanover, Maryland, USA). The model was implemented using the LSODA differential equation solver (ADVAN13) subroutine in NONMEM (47). The estimation was performed using the first-order conditional estimation with interaction method (FOCE-I), assuming no random effects on the model structural parameters given that only mean data was available for the IV plasma concentration profile (30). For the estimation, both the data and model output were transformed into natural logarithms (transform both sides) and an additive error model (on the log scale) was assumed for the residual unexplained variability (RUV). $C L_{i n t(u)}$ and $K_{p u \text { tissues }}$ were also logged for the purposes of parameter estimation. The latter was done to stabilize the estimation and to prevent the model parameters taking negative values in the differential equations $(48,49)$.

\section{Expansion of the mSAT Model for Mechanistic Bioavailability Predictions}

The mSAT model is a multi-compartmental absorption model that has been recently proposed and used for the prediction of the fraction absorbed using different intestinal permeability approaches (26). The model structure was based on the original Compartmental Absorption and Transit (CAT) model developed in the late 1990s by $\mathrm{Yu}$ and co-workers (50-52). The main difference with respect to the CAT model, however, was that the new model describes the small intestine with only three anatomically defined compartments, duodenum, jejunum and ileum, instead of seven in the CAT model. In order to adequately describe the mean small intestinal transit time (SITT) with a reduced number of compartments, the mSAT model was implemented with a Weibull transit function that was optimized based upon the same SITT data used for the development of the CAT model $(26,52)$. As in the first version of the CAT model, the mSAT model structure was kept relatively simple as the initial goal was only to predict the fraction absorbed based on permeability data (26).

For this study, the mSAT model was expanded for the mechanistic prediction of oral absorption and bioavailability following a similar structure to that of the ACAT and ADAM models implemented within GastroPlus ${ }^{\mathrm{TM}}$ and the SimCYP ${ }^{\circledR}$ simulator, respectively $(8,53)$.

The expanded mSAT model structure is shown in Fig. 1b. The main segments of the mSAT model are stomach (ST), duodenum (DUO), jejunum (JEJ), ileum (ILE) and ascending colon (COL) (26). For each $n$th GI segment, the drug amount can be modelled either in the solid $\left(A_{\text {solid, } n}\right)$ state or the dissolved state $\left(A_{\text {diss }, n}\right)$, where no explicit compartments were implemented for the drug contained in the formulation. The model assumes that all the GI compartments are well mixed (50-52), only dissolved drug can be absorbed (54), absorption can only occur by means of non-saturable process, no significant absorption can occur from the stomach compartment (50), no drug degradation can occur in the luminal portions of the GI compartments and the lengths of the GI segment are representative of their anatomical lengths $(37,55)$. The model was implemented in MATLAB 2014a (The MathWorks Inc., Natick, MA, USA), and the ordinary differential equations (ODE) were numerically evaluated using the ode15s solver for stiff ODEs. The equations describing the drug's dynamics within the compartments of the mSAT model are summarized below (Eqs. 9-18), and the model details are given in the following sections.

\section{Stomach}

$$
\begin{aligned}
& \frac{d A_{\text {solid }, s t}}{d t}=S T E P_{s t} \times I N P U T(t)-k_{G E} \times A_{\text {solid }, s t}-D R_{s t} \\
& \frac{d A_{d i s s, s t}}{d t}=D R_{s t}-k_{G E} \times A_{\text {diss }, s t}
\end{aligned}
$$

\section{Duodenum}

$$
\begin{aligned}
& \frac{d A_{\text {solid,duo }}}{d t}= S T E P_{d u o} \times \operatorname{INPUT}(t)+k_{G E} \\
& \times A_{\text {solid,st }}-D R_{d u o}-w(t)_{d u o} \times A_{\text {solid,duo }} \\
& \frac{d A_{\text {diss }, \text { duo }}}{d t}=k_{G E} \times A_{\text {diss }, s t}+D R_{d u o}-\left(w(t)_{d u o}+k_{a, d u o}\right) \times A_{\text {diss }, \text { duo }}
\end{aligned}
$$

Jejunum and Ileum $(n=2,4)$

$$
\begin{aligned}
\frac{d A_{\text {solid }, n}}{d t}= & S T E P_{n} \times \operatorname{INPUT}(t)+w(t)_{n-1} \\
& \times A_{\text {solid }, n-1}-D R_{n}-w(t)_{n} \times A_{\text {solid }, n} \\
\frac{d A_{\text {diss }, n}}{d t}= & w(t)_{n-1} \times A_{\text {diss }, n-1}+D R_{n}-\left(w(t)_{n}+k_{a, n}\right) \times A_{\text {diss }, n} \\
w(t)_{n}= & \frac{\beta}{f_{L S I, n} \times S I T T \times \gamma} \times\left(\frac{t}{f_{L S I, n} \times S I T T \times \gamma}\right)^{\beta-1}
\end{aligned}
$$

\section{Ascending Colon}

$\frac{d A_{\text {solid, }, c o l}}{d t}=S T E P_{\text {col }} \times \operatorname{INPUT}(t)+w(t)_{i l e} \times A_{\text {solid,ile }}-D R_{c o l}-k_{t, c o l} \times A_{\text {solid,col }}$

$\frac{d A_{\text {diss }, c o l}}{d t}=w(t)_{i l e} \times A_{\text {diss }, i l e}+D R_{c o l}-\left(k_{t, c o l}+k_{a, c o l}\right) \times A_{\text {diss }, c o l}$ 
All the Intestinal Segments

$V_{e n t, n} \times \frac{d C_{e n t, n}}{d t}=k_{a, n} \times A_{d i s s, n}-\left(Q_{e n t, n}+C L_{e n t, n}\right) \times C_{e n t, n}$

\section{Drug Transit}

Drug mass in the stomach compartment (solid and dissolved) was transferred to the adjacent segment by means of a first-order process controlled by the gastric emptying rate constant, $k_{\mathrm{GE}}(56-58)$. In the case of disintegrating solid immediate-release (IR) dosage forms (or suspensions), the initial conditions (at $t=0$ ) in the stomach compartment (Eq. 9) were set to the administered dose $\left(A_{\text {solid,st }(0)}=\right.$ dose $)$. However, in the case of non-disintegrating solid dosage forms, the solid drug was transferred to the adjacent segment by means of a discrete process depending upon the mean residence time (MRT) in the stomach $\left(1 / \mathrm{k}_{\mathrm{GE}}\right)$; this also applied to the rest of the GI compartments.

For non-disintegrating solid dosage forms, transfer of the solid mass was implemented with a step function (STEP) following the method described by Hénin and co-workers (59). When the STEP function is used, the initial conditions of the stomach compartment are set to zero and an input function $(\operatorname{INPUT}(t))$ for the solid mass needs to be used. This INPUT(t) function can take any form, for example a zero order input rate, simulated release profile, an in vitro release profile, etc. More details about the implementation of the STEP ${ }_{n}$ function in the mSAT model can be found in Sect. 1 of the Supplementary Material. For the small intestinal compartments, the transit of the drug particles to the adjacent segment (solid and dissolved) was implemented by a timevarying Weibull function, $w(t)_{n}$ (Eq. 15), where $\beta$ and $\gamma$ are dimensionless coefficients with a value of 2.01 and 1.57 , respectively (26), $f_{L S I, n}$ is the fractional length of the $n$th small intestinal segment (with respect to the total length of the small intestine, $L S I), f_{L S I, n}$ was assumed as $0.08,0.37$ and 0.55 for duodenum, jejunum and ileum, respectively (55). For the ascending colon, the drug transit was assumed as a first-order process depending upon the ascending colon transit rate constant $\left(k_{t, c o l}\right)$. The use of a linear transit model and rate constant for the colon segment was based on the fact that the transit time in the whole colon (from cecum to deciding colon) has been successfully described by using such a model by Bouchoucha and co-workers, where they described transit of markers using three transit compartment, representing ascending, transverse and descending colon or right, left and recto-sigmoid colon, respectively $(60,61)$

\section{Dissolution and Solubility}

The segment-dependent dissolution rate $\left(D R_{n}\right)$ can be either inputted from in vitro dissolution studies or predicted using derivations of the Noyes-Withney/NernstBrunner equation for drug dissolution (62). Particularly for $\mathrm{OXY}$, the dissolution rate was predicted by using a modification of the model proposed by Wang and
Flanagan for spherical particles dissolving over time $(53,63,64)$ as shown in Eq. 19,

$$
\begin{aligned}
-D R_{n}=\frac{d A_{\text {solid }, n}}{d t}= & -\frac{3 \times D_{a q} \times A_{\text {solid }(0), n}^{1 / 3} \times A_{\text {solid }, n}^{2 / 3}}{\rho_{p} \times r_{0}} \\
& \times\left(S_{n}-\frac{A_{\text {diss }, n}}{V_{\text {lum }, n}}\right)\left(\frac{1}{h_{\text {eff }}(t)}+\frac{1}{r(t)}\right)
\end{aligned}
$$

where $A_{\text {solid }(0), n}$ is the initial amount of solid drug in the given GI segment, this mass was calculated in MATLAB by integrating the cumulative amount of solid drug entering each intestinal segment at each iteration, whereas for the stomach compartment, this mass was assumed equals to the dose, $D_{a q}$ is the aqueous diffusion coefficient $\left(\mathrm{cm}^{2} / \mathrm{h}\right), r_{0}$ is the initial particle radius $(\mathrm{cm}), \rho_{p}$ is the particle density $(\mathrm{mg} / \mathrm{mL})$, $S_{n}$ is the segment-dependent aqueous solubility $(\mathrm{mg} / \mathrm{mL})$, $V_{\text {lum }, n}$ is the segment-dependent luminal fluid volume $(\mathrm{mL})$, $h_{\text {eff }}(t)$ is the effective diffusion layer thickness $(\mathrm{cm})(65,66)$ and $r(t)$ is the particle radius $(\mathrm{cm})$ at a given time. The main assumptions of Eq. 19 are that the spherical particles are in a well-stirred media, the particles dissolve isotopically, that the total number of particles remains constant across the system, there is an immediate precipitation when the dissolution rate takes positive value (i.e. no super-saturation was allowed in the model) and all the particles have the same initial radius $\left(r_{0}\right)(63)$. The time-varying radius for the dissolving spherical particles was calculated using Eq. $20(63,64,67)$. When the particle radius reached a critical value of $10^{-9} \mathrm{~cm}$, the dissolution was assumed complete and the dissolution rate was assumed to be zero. $h_{\text {eff }}(t)$, on the other hand, was assumed to be equal to $r(t)$ in the case of particles with radius smaller than $30 \mu \mathrm{m}$; otherwise, it was assumed equal to an empirical maximum value of $30 \mu \mathrm{m}(53,66-69)$.

$$
r(t)=r_{0} \times\left(\frac{A_{\text {solid }, n}}{A_{\text {solid }(0), n}}\right)^{1 / 3}
$$

OXY's segmental solubility $\left(S_{n}\right)$ was calculated according to its intrinsic solubility $\left(S_{0}\right)$, pKa and segment-depended $\mathrm{pH}$ with the use of the Henderson-Hasselbalch equation for monoprotic bases (70). Details of such calculations can be found in Sect. 4 of the Supplementary Material.

Luminal fluid volumes $\left(V_{\text {lum, },}\right)$ were determined using an empirical fluid dynamics model with similar characteristics to the model proposed by Jamei and co-workers (53). The model assumes that fluid movements along the GI tract are driven by gastric emptying and intestinal transit time, taking into account volume fluctuations due to fluid intake, intestinal fluid secretion and reabsorption (53). The empirical nature of the model is due to the fact that the GI fluid secretion and reabsorption parameters were obtained by fitting the model to free intestinal water data (71). This data was obtained by magnetic resonance imaging (MRI) after the intake of $240 \mathrm{~mL}$ of water in 12 healthy volunteers under fasting conditions (71). The details of the model and the fitting can be found in Sect. 2 of the Supplementary Material. 


\section{Intestinal Absorption}

Absorption of the dissolved drug was modelled as a firstorder process depending upon a segment-specific first-order absorption rate constant $\left(k_{a, n}\right)$ as shown by Eq. 21

$k_{a, n}=\frac{2 \times P_{e f f} \times D F \times S A E F_{n} \times I_{\text {ratio }, n}}{r_{n}}$

where $P_{\text {eff }}$ is the drug's effective intestinal permeability, $r_{n}$ is the radius of the intestinal segment, $D F$ is the degree of flatness coefficient that accounts for changes in surface area to volume ratio due to the elliptical shape of the human intestine (compared to a cylinder) and was assumed to be 1.7 as suggested by Sugano (2009) (72), and $S A E F_{n}$ is the ratio between surface area amplification factors of the $n$th intestinal segment with respect to that of the jejunum, where $P_{\text {eff }}$ is measured $(26,73)$. This ratio takes into account regional variations in drug absorption due to changes in the available mucosal surface area (mSA), and it is necessary for the implementation or segment-dependent intestinal permeation (26). $S A E F_{n}$ differences were implemented using the Method 3 (M3) proposed by Olivares-Morales and co-workers (2015), where $S A E F_{n}$ takes values of $0.49,1.00,0.58$ and 0.033 for the duodenum, jejunum, ileum and ascending colon, respectively, and $I_{\text {ratio, } n}$ is the ratio between the fraction of unionized drug at the segment's $\mathrm{pH}$ with respect to that in the jejunum $\left(I_{\text {ratio, } n}=f_{\text {unionized }, n} / f_{\text {unionized,jejunum }}\right)$. This ratio takes into account regional differences in intestinal permeability due to changes in ionization compared to that of the upper jejunum, where $P_{\text {eff }}$ is measured $(73,74) . I_{\text {ratio, } n}$ was calculated using the Henderson-Hasselbalch equation based on the segment's luminal $\mathrm{pH}$ and OXY's pKa (Sect. 4.1 of the Supplementary Material).

\section{Enterocyte Compartments and Intestinal Metabolism}

Mechanistic enterocyte compartments were implemented in the mSAT model to predict OXY's regional intestinal metabolism. Equation 18 shows the general structure of such compartments where $C_{e n t, \mathrm{n}}$ is the OXY's concentration in the $n$th enterocyte compartment $(\mathrm{mg} / \mathrm{L})$ and $V_{\text {ent,n }}$ is the volume of the enterocyte compartment (L). These volumes were calculated by multiplying the $m S A_{n}$ of the give intestinal segment by the respective enterocyte height (without accounting for the surface area expansion due to microvilli) $(9,27), Q_{e n t, n}$ is the villous blood flow of the $n$th enterocyte compartment $(\mathrm{L} / \mathrm{h})$ and $\mathrm{CL}_{\text {ent, } n}$ is the segment-dependent enterocyte clearance. This clearance was calculated according to Eq. 22

$C L_{\text {ent }, n}=\sum_{j=1}^{m}\left(\frac{f m_{C Y P j} \times C L_{\mathrm{int}(u)} \times A_{C Y P j(\text { ent }), n}}{A_{C Y P j(\text { liver })}}\right)$

where $f m_{C Y P j}$ is the fraction of the total intrinsic clearance $\left(C L_{\text {int }(u)}\right)$ associated to the $j$ th CYP isoform. This value was derived from the in vitro data reported by Mizushima and coworkers (75), and the details of such calculations can be found in Sect. 4.2 of the Supplementary Material. $A_{C Y P j(\text { liver })}$ is the mean liver abundance of the $j$ th CYP isoform (pmol/mg microsomal protein) (76), and $A_{C Y P j(e n t), n}$ is the absolute abundance of the $j$ th CYP isoform in the $n$th enterocyte compartment (pmol) $(22,77,78)$. Equation 22 assumes that the intrinsic clearances (per pmol of enzyme) are equal in both the liver and the intestinal wall $(40,79)$ and that there is no binding of the drug in the enterocyte compartments $\left(\mathrm{fu}_{\mathrm{gut}}=1\right)$ $(11,80)$. All the system-related parameters for the mSAT model were derived from the literature, and they are summarized in Table I.

Finally, the model was implemented with mass balance equations that allowed the estimation of the extent of drug dissolution, absorption $\left(f_{a b s}\right)$ and availability in the intestine and the liver $\left(F_{G}\right.$ and $\left.F_{H}\right)$. The extended model was combined with the disposition model developed in the previous section and implemented together in MATLAB.

\section{OXY's Oral PK Simulations and Relative Bioavailability Predictions}

OXY oral pharmacokinetic profile was mechanistically predicted using the combined mSAT absorption and disposition model (Fig. 1). For the predictions, OXY's drug-specific input parameters were either derived from literature or calculated using in silico equations. A summary of the parameters and their values are provided in Table II. More details about the parameter selection and/or calculations can be found in Sect. 4 of the Supplementary Material.

Two different oral pharmacokinetic studies were predicted using the mSAT model. In the first study, the pharmacokinetics of OXY was investigated after the administration of three 5-mg IR tablets (every $5 \mathrm{~h}$ ) to eight healthy volunteers, four of them participating in the IV study used for the optimization of the disposition model (30). The tablets were administered under fasting conditions together with $100 \mathrm{~mL}$ of water, and blood samples were collected up to $15 \mathrm{~h}$ post-dose. OXY plasma concentrations were measured using a validated assay (30). This study was simulated with the intention to evaluate the model capacity to mechanistically predict OXY's oral pharmacokinetic, particularly given the fact that some of the study participants were also part of the IV study used for the development of OXY's disposition model (30). The model prediction were evaluated graphically and contrasted with observed mean clinical data in terms of accuracy of the prediction of mean pharmacokinetic parameters such as absolute bioavailability $(F)$, area under the curve (AUC) and maximum plasma concentration $\left(C_{\max }\right)$.

The second study was a relative bioavailability study between OXY's IR tablet and its controlled-release (OROS () ) formulation. The clinical data of this study was kindly provided by Janssen Pharmaceutica. The study was conducted in 41 healthy volunteers, males and females, where each subject received three 5-mg IR release tablets (every $8 \mathrm{~h}$ ) and one 10-mg controlled-release (OROS $®)$ formulation in a cross-over fashion. The formulations were administered in the morning under fasted conditions together with a 240-mL glass of water. Blood samples were collected up to $48 \mathrm{~h}$ post-dose and were analysed for OXY using a validated LC-MS/MS assay (81). In contrast to the previous study, a stereo-selective assay was employed for the determination of OXY plasma concentrations and the concentrations of OXY 
Table II. OXY's Drug-Related Parameters Employed for the Simulations (Racemic Mixture and Isomers)

\begin{tabular}{|c|c|c|c|c|c|c|}
\hline Parameter [units] & OXY racemic & R-OXY & & \multicolumn{2}{|c|}{ S-OXY } & Ref. $^{\text {a }}$ \\
\hline Molecular weight $(\mathrm{MW})[\mathrm{g} / \mathrm{mol}]$ & 357.5 & - & & \multicolumn{2}{|c|}{-} & S5 \\
\hline pKa (base) & 8.04 & - & & \multicolumn{2}{|l|}{-} & S5 \\
\hline $\log \mathrm{D}_{7.4}$ & 2.98 & - & & \multicolumn{2}{|l|}{-} & S5 \\
\hline $\log \mathrm{P}$ & 3.71 & - & & \multicolumn{2}{|l|}{-} & S5 \\
\hline Intrinsic solubility $\left(S_{0}\right)[\mathrm{mg} / \mathrm{mL}]$ & 0.012 & - & & \multicolumn{2}{|l|}{-} & S5 \\
\hline Particle density $\left(\rho_{p}\right)[\mathrm{mg} / \mathrm{mL}]$ & $1.20 \times 10^{3}$ & - & & \multicolumn{2}{|l|}{-} & S5 \\
\hline Initial particle radius $\left(r_{0}\right)[\mathrm{cm}]$ & $1.00 \times 10^{-3}$ & - & & \multicolumn{2}{|l|}{ - } & S5 \\
\hline Aqueous diffusion coefficient $\left(D_{a q}\right)\left[\mathrm{cm}^{2} / \mathrm{h}\right]$ & 0.025 & - & & \multicolumn{2}{|c|}{-} & S5 \\
\hline Blood to plasma ratio $(B P)$ & 0.686 & 0.71 & & \multicolumn{2}{|c|}{0.682} & S5 \\
\hline Fraction unbound in plasma $\left(f_{u p}\right)$ & $3.40 \times 10^{-3}$ & $4.70 \times 10^{-3}$ & & \multicolumn{2}{|c|}{$2.75 \times 10^{-3}$} & S5 \\
\hline Apparent permeability $\left(P_{a p p}\right)\left[\times 10^{-6} \mathrm{~cm} / \mathrm{s}\right]$ & 21.9 & - & & \multicolumn{2}{|c|}{-} & S5 \\
\hline Jejunal effective permeability $\left(P_{\text {eff }}\right)\left[\times 10^{-4} \mathrm{~cm} / \mathrm{s}\right]$ & 4.31 & - & & \multicolumn{2}{|c|}{-} & S5 \\
\hline$K_{\text {pu(liver) }}$ & $1.18 \times 10^{3}$ & $1.00 \times 10^{3}$ & & \multicolumn{2}{|c|}{$1.53 \times 10^{3}$} & S5 \\
\hline$K_{\mathrm{pu}, \text { tissues }}$ & Estimated & - & & \multicolumn{2}{|c|}{-} & See methods \\
\hline $\mathrm{CL}_{\text {int(u) }}$ & Estimated & - & & \multicolumn{2}{|l|}{-} & See methods \\
\hline$R / S_{\text {CLint,ratio }}$ & 1 & 0.89 & & \multicolumn{2}{|l|}{1.1} & S5 \\
\hline $\mathrm{fm}_{\mathrm{CYP} 3 \mathrm{~A} 4}$ & 0.80 & 0.79 & & \multicolumn{2}{|l|}{0.81} & S5 \\
\hline $\mathrm{fm}_{\mathrm{CYP} 2 \mathrm{C} 9}$ & 0.12 & 0.13 & & \multicolumn{2}{|l|}{0.11} & S5 \\
\hline $\mathrm{fm}_{\mathrm{CYP} 2 \mathrm{C} 19}$ & 0.07 & 0.08 & & \multicolumn{2}{|l|}{0.05} & S5 \\
\hline $\mathrm{fm}_{\mathrm{CYP} 2 \mathrm{D} 6}$ & 0.01 & 0.00 & & \multicolumn{2}{|l|}{0.03} & S5 \\
\hline & \multicolumn{6}{|c|}{ Segment } \\
\hline Regional luminal parameters & ST & DUO & JEJ & ILE & $\mathrm{COL}$ & \\
\hline Segmental solubility $\left(S_{n}\right)[\mathrm{mg} / \mathrm{mL}]$ & 12 & 0.54 & 0.34 & 0.12 & 0.43 & S5 \\
\hline Luminal ionization ratio $\left(I_{\text {ratio }, n}\right)$ & $\mathrm{n} / \mathrm{a}$ & 0.64 & 1.00 & 2.94 & 0.80 & S5 \\
\hline
\end{tabular}

"-" indicates that the parameter was the same as for racemic oxybutynin

${ }^{a}$ Details and the sources of each parameter value can be found in Sect. 4.5 of the Supplementary Material (Table S5)

enantiomers, $R$ and $S$-oxybutynin, were reported (81). It has been shown that OXY enantiomers display stereo-selective pharmacokinetics, mainly attributable to differences in volume of distribution and clearance between the enantiomers (75). To overcome this issue, the aforementioned differences were accommodated into the mSAT model predictions, adapting OXY's parameters with the observed in vitro parameters for each enantiomer $(75,82)$. For instance, changes in volume of distribution between enantiomers were mainly attributed to plasma protein-binding differences $(75,82)$. Hence, stereo-selective plasma protein binding was implemented in the model by employing the reported $f_{u p}$ for each enantiomer (Table II). This led to changes in the volume of distribution as the $K_{b, t i s s u e}$ is related to $f_{u p}$ by Eq. 5 . The clearance differences, on the other hand, were accommodated assuming that the $\mathrm{CL}_{\text {int,(u) }}$ of the racemic mixture represented an average between the intrinsic clearances of the enantiomers. Thus, the enantiomer-specific $\mathrm{CL}_{\text {int(u) }}$ was calculated by multiplying the $\mathrm{CL}_{\mathrm{int}(\mathrm{u})}$ value of the racemic mixture by the $\mathrm{CL}_{\text {int(u) }}$ ratio between the enantiomers $\left(R / S_{C \text { int, ratio }}\right)$. The latter parameter was defined for each enantiomer as the ratio between the observed in vitro $\mathrm{CL}_{\text {int(u) }}$ of the given enantiomer and the average in vitro $\mathrm{CL}_{\mathrm{int}(\mathrm{u})}$ between them. More details on the derivation of the aforementioned parameters can be found in Sect. 4.4 of the Supplementary Material.

For the relative bioavailability predictions, both IR and OROS $®$ formulations were simulated as per the study protocol, whereas an additional IV profile was simulated to estimate the absolute bioavailability of each formulation. The drug was assumed to be administered as a racemic mixture for prediction of the luminal processes (i.e. dissolution, release). However, once the drug entered the intestinal wall compartments of the mSAT model, the dose was divided into enantiomer fractions. The compartments within the mSAT model were used to prospectively estimate bioavailability fractions for each formulation $\left(f_{a}, F_{G}\right.$ and $\left.F_{H}\right)$. In the case of the OROS $®$ formulation, the observed mean in vitro release profile was used as the INPUT function (Eq. 9). The in vitro release profile was digitized from the literature $(81,83)$. This profile was measured in a USP apparatus VII in different dissolution media such as water, simulated gastric fluid (SGF) and simulated intestinal fluid (SIF) (83). Given the results of the release study, it was assumed that OXY's release rate from the OROS $\AA$ formulation was not affected by luminal changes in $\mathrm{pH}$ and/or fluid volumes (83). The INPUT $T_{n}$ profile can be found in the Sect. 4.3 of the Supplementary Material. Since OXY content in the OROS ${ }^{\circledR}$ is released as a suspension $(84,85)$, the dissolution rate of the suspended drug was calculated using Eq. 19.

Lastly, an additional simulation was conducted for the OROS $®$ formulation using the classical approach for intestinal permeability, i.e. Method 1 (M1) in (26), and $S A E F_{n}$ ratio was assumed 1 in all segments. This was done in order to evaluate the benefits of implementing the segment-dependent permeability approach for the prediction of OXY's pharmacokinetics when administered as an OROS $®$ formulation (26).

\section{RESULTS}

\section{OXY's Disposition Parameter Estimation}

The estimation of the parameters for the semiphysiological disposition model was successfully completed, and the parameters estimates are summarized in Table III. 
Table III. Estimated OXY Disposition Parameters from the IV Infusion Fit

\begin{tabular}{lll}
\hline Parameter & Estimate & RSE (\%) \\
\hline $\mathrm{CL}_{\text {int }(u)}[\mu \mathrm{L} / \mathrm{min} / \mathrm{mg}]$ & 3944 & $5.0 \%$ \\
$Q_{\text {tissue }, 1}\left(f_{\mathrm{CO}, 1}\right)[\mathrm{L} / \mathrm{h}]^{\mathrm{a}}$ & $9.76(0.0346)$ & $23 \%$ \\
$Q_{\text {tissue, } 2}\left(f_{\mathrm{CO}, 2}\right)[\mathrm{L} / \mathrm{h}]^{\mathrm{a}}$ & $253(0.897)$ & $1.9 \%$ \\
$Q_{\text {tissue, } 3}\left(f_{\mathrm{CO}, 3}\right)[\mathrm{L} / \mathrm{h}]^{\mathrm{a}}$ & $19.4(0.0688)$ & $16 \%$ \\
$V_{\text {tissue }, 1}\left(f_{\mathrm{BW}, 1}\right)[\mathrm{L}]^{\mathrm{a}}$ & $50.8(0.775)$ & $3.1 \%$ \\
$V_{\text {tissue, } 1}\left(f_{\mathrm{BW}, 1}\right)[\mathrm{L}]^{\mathrm{a}}$ & $6.42(0.098)$ & $19 \%$ \\
$V_{\text {tissue, } 1}\left(f_{\mathrm{BW}, 1}\right)[\mathrm{L}]^{\mathrm{a}}$ & $8.33(0.127)$ & $8.9 \%$ \\
$K_{\text {pu,tissues }}$ & 469 & $10 \%$ \\
$R U V[\% \mathrm{CV}]^{\mathrm{b}}$ & 6.54 & $35 \%$ \\
\hline
\end{tabular}

The relative standard errors (RSE) were calculated as: 100× (standard error/estimate). For $\mathrm{CL}_{\text {int(u) }}$ and $K_{\text {pu,tissue, the RSE are }}$ reported in the normal scale, and these were calculated using normal/ log-normal reverse algebra. The estimates of the fractions of the $\mathrm{CO}$ and BW (hence blood flows and volumes) were obtained on the logistic scale. These values were transformed back to fractions, in the logistic-normal scale, using Eq. 8. The RSE for such fractions were obtained by simulations: $1 \times 10^{7}$ random samples were drawn from a multivariate-normal distribution and then transformed back to the logistic-normal scale, where summary statistics (mean and standard deviations) of the resulting vectors were calculated using MATLAB 2014a. More details of the approach are given in (42)

${ }^{a}$ Values in parenthesis represent the estimated fractions of $\mathrm{CO}$ and BW

${ }^{b} \mathrm{RUV}$ is expressed as a coefficient of variation (\%CV) calculated as: $100 \times \sqrt{e^{\sigma^{2}}-1}$

The structural model parameters were obtained with relative good precision; all the relative standard errors (RSE) were below $25 \%$. The model provided a good fit to the infusion data as shown in Fig. 2 (30). The NONMEM code for the estimation can be found in Sect. 6 of the Supplementary Material.

\section{Mechanistic Prediction of OXY's Oral Pharmacokinetics}

The predicted oral pharmacokinetic profile of OXY's IR tablet ( 3 doses, every $5 \mathrm{~h}$ ) is shown in Fig. 3. There was a good agreement between the observed clinical data and the mSAT model prediction (30). The predicted $\mathrm{AUC}_{0-15 \mathrm{~h}}$ was $32.5 \mathrm{ng} * \mathrm{~h} / \mathrm{mL}$, comparable with the reported value (mean \pm $\mathrm{SEM}$ ) of $33.7 \pm 7.9 \mathrm{ng} * \mathrm{~h} / \mathrm{mL}$ (30). $C_{\max }$, on the other hand, was predicted to be $6.24 \mathrm{ng} / \mathrm{mL}$, whereas the reported $C_{\max }$ for the third dose on day 1 was $7.55 \pm 2.22 \mathrm{ng} / \mathrm{mL}$ (30). The estimated absolute bioavailability for the racemic OXY was $5.94 \%$, whereas the reported absolute bioavailability was 6.2 $\pm 1.2 \%$ (30).

\section{Relative Bioavailability Between IR and OROS® Formulation}

The mSAT model was able to predict the pharmacokinetics of OXY enantiomers when formulated as IR and OROS $®$. The pharmacokinetic predictions of the $R$ isomer (R-OXY) are shown Fig. 4, whereas the predictions of SOXY can be found in the Supplementary Material (Fig. S6). Table IV summarizes the observed and predicted relevant pharmacokinetic parameters, stratified by formulation and enantiomers. There was a good agreement between the observed clinical data and the mSAT predictions (Fig. 4a and Fig. S6). Nevertheless, a general trend towards the underestimation of the oral pharmacokinetics of the IR formulation could be observed for both enantiomers (Fig. 4a and Fig. S6A). This underestimation tended to be more prominent for the $S$ enantiomer than for the $R$ enantiomer, both in terms of $C_{\max }$ and $\mathrm{AUC}_{0-48}$ (Table IV). The predicted $C_{\max }$ and $\mathrm{AUC}_{0-48}$ were within $\pm 20 \%$ of the observed values for R-OXY, whereas the bias for the $S$ enantiomer was -51 and $-37 \%$ for $C_{\max }$ and $\mathrm{AUC}_{0-48}$, respectively. For the OROS $\AA$ formulations, underestimation of the pharmacokinetic parameters was also observed, though to a lesser extent than for the IR formulation. The latter was particularly observed for the $R$ enantiomer (Fig. 4b) where both $\mathrm{AUC}_{0-48}$ and $C_{\max }$ were within $6 \%$ of the observed values

The parameters for the $S$ enantiomer, on the other hand, showed a bias between 20 and $28 \%$ for $\mathrm{AUC}_{0-48}$ and $C_{\max }$, respectively.

The relative bioavailability $\left(F_{r e l}\right)$ predictions of the OROS ${ }^{\circ}$ formulation were consistent with those of the observed values; both enantiomers displayed higher $F_{r e l}$ when formulated as OROS ${ }^{\circledR}$ compared to the IR. The $F_{\text {rel }}$ predictions tended to be overestimated by a factor of $20 \%$.

Mechanistic predictions of the intestinal processes driving oral absorption and bioavailability are shown in Fig. 5, and the parameters are summarized in Table IV. Both enantiomers IR were predicted to be well absorbed from the IR formulation, and the $f_{a b s}$ values were close to 1 . For the OROS $®$ formulation, this fraction was predicted to be reduced by almost a $70 \%$ (Table IV). The predicted intestinal first-pass metabolism for the IR formulation was high $\left(F_{G} \leq\right.$ $0.13)$, whereas for the OROS $®$ formulations, the $F_{G}$ was predicted to be almost eightfold higher. For the IR formulation, the majority of the absorption and intestinal elimination was predicted to occur in the jejunum segment (Fig. 5), while for the OROS $\AA$ formulation, the absorption was predicted to occur mainly in the distal ileum and ascending colon, with a limited intestinal first-pass only in the ileal segment. The predicted hepatic availability $\left(F_{H}\right)$ for both formulations was practically the same.

Finally, Fig. 6 shows the simulated pharmacokinetic profile obtained employing the two different permeability approaches (R-OXY). It can be noticed that when using the classical approach for permeability, i.e. employing the same $P_{\text {eff }}$ values for all the intestinal segments, a significant overestimation of the distal absorption would have been predicted for OXY. Therefore, the use of the newly proposed regional permeability approach (M3) gives rise to a much more accurate prospective prediction (26), particularly important given the type of nature of the drug (BCS class 1) and the prolonged release from the OROS ${ }^{\circ}$ formulation $(24 \mathrm{~h})$.

\section{DISCUSSION}

The recently proposed mSAT model was successfully expanded and applied to the mechanistic prediction of the oral bioavailability differences between OXY's IR and OROS $₫$ formulation in a purely prospective fashion. The approach employed herein involved several steps that were necessary to appropriately distinguish between OXY's disposition and absorption processes in the model predictions. 


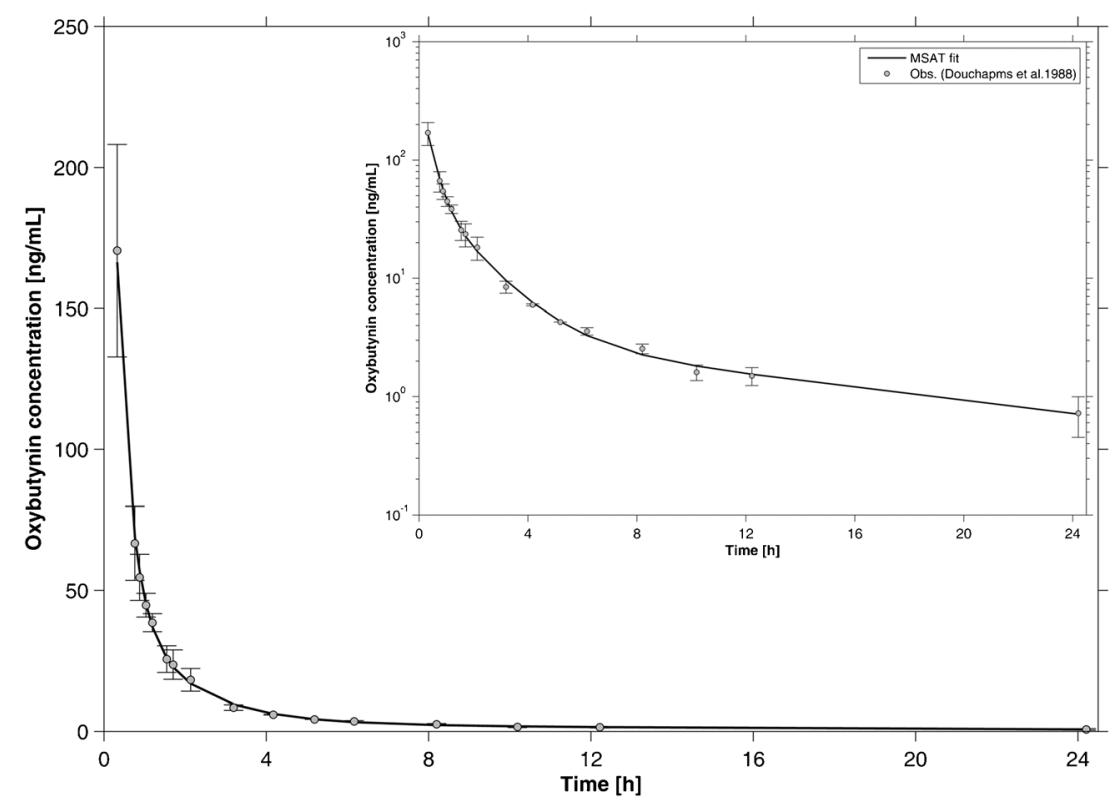

Fig. 2. OXY's disposition model fit to the 5-mg IV infusion data. The solid black line represents the mSAT model prediction, whereas the solid grey circles and error bars are the respective mean and standard error of the mean (SEM) of the observed clinical data (digitized from (30)). The insert shows the same plot on the semi-logarithmic scale

The first step consisted in the development of a disposition model capable of describing OXY's distribution and elimination processes as well as to mechanistically account for its pre-systemic extraction when combined with the absorption model. Several structures were evaluated for the disposition model, from a three-compartment model with a mechanistic liver compartment to a whole body PBPK model. The chosen model was that of Fig. 1a. This model represents a hybrid between the full PBPK model and the compartmental model, providing the flexibility of the compartmental model for the fitting purposes, yet retaining the mechanistic nature of the PBPK model where it was needed, such as in the liver compartment. As previously described, the model was constrained in terms of the volumes of the empirical tissues and their blood flows following the approach suggested by Cao and Jusko (33). These constraints were implemented during the estimation process in NONMEM with the help of the logistic-normal transformations proposed by Tsamandouras and co-workers (2015). As shown in Fig. 2, the fitted model provided an accurate

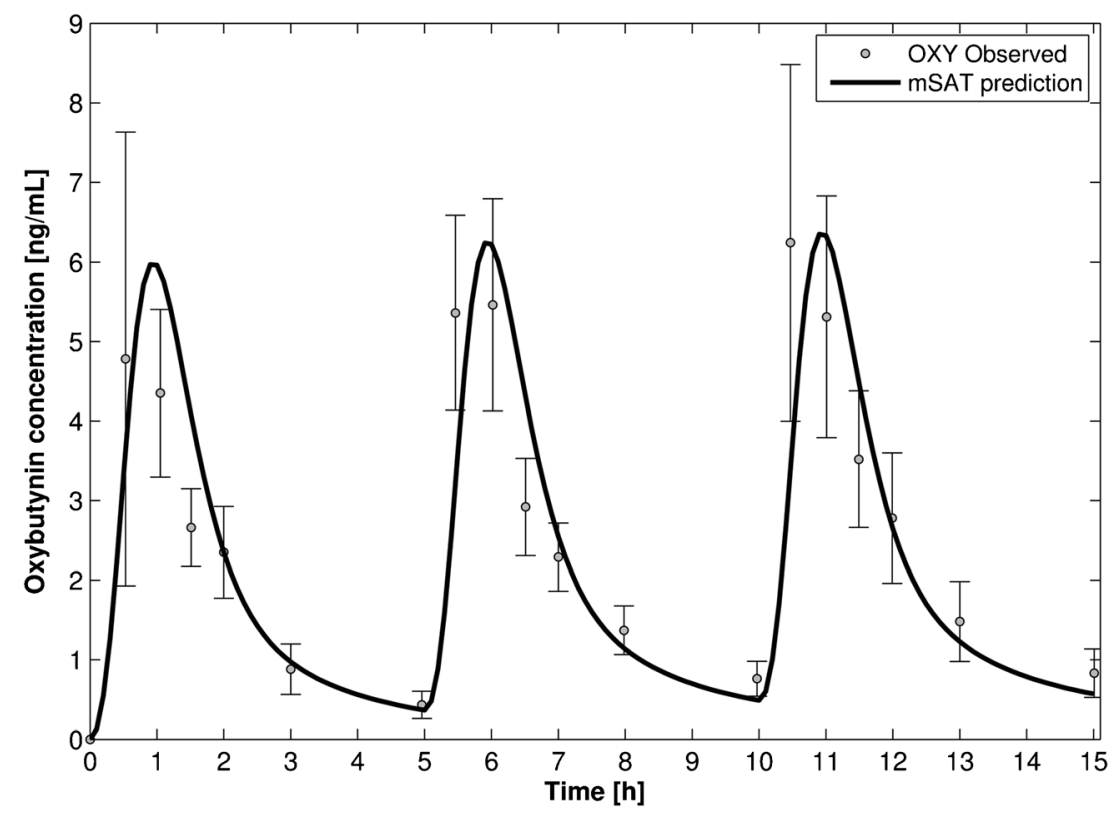

Fig. 3. Model predictions of OXY oral pharmacokinetics (racemic) after a multiple dose administration. The solid black line represents the mSAT model prediction, whereas the solid grey circles and error bars are the respective mean and standard error of the mean (SEM) of the observed clinical data (digitized from (30)) 

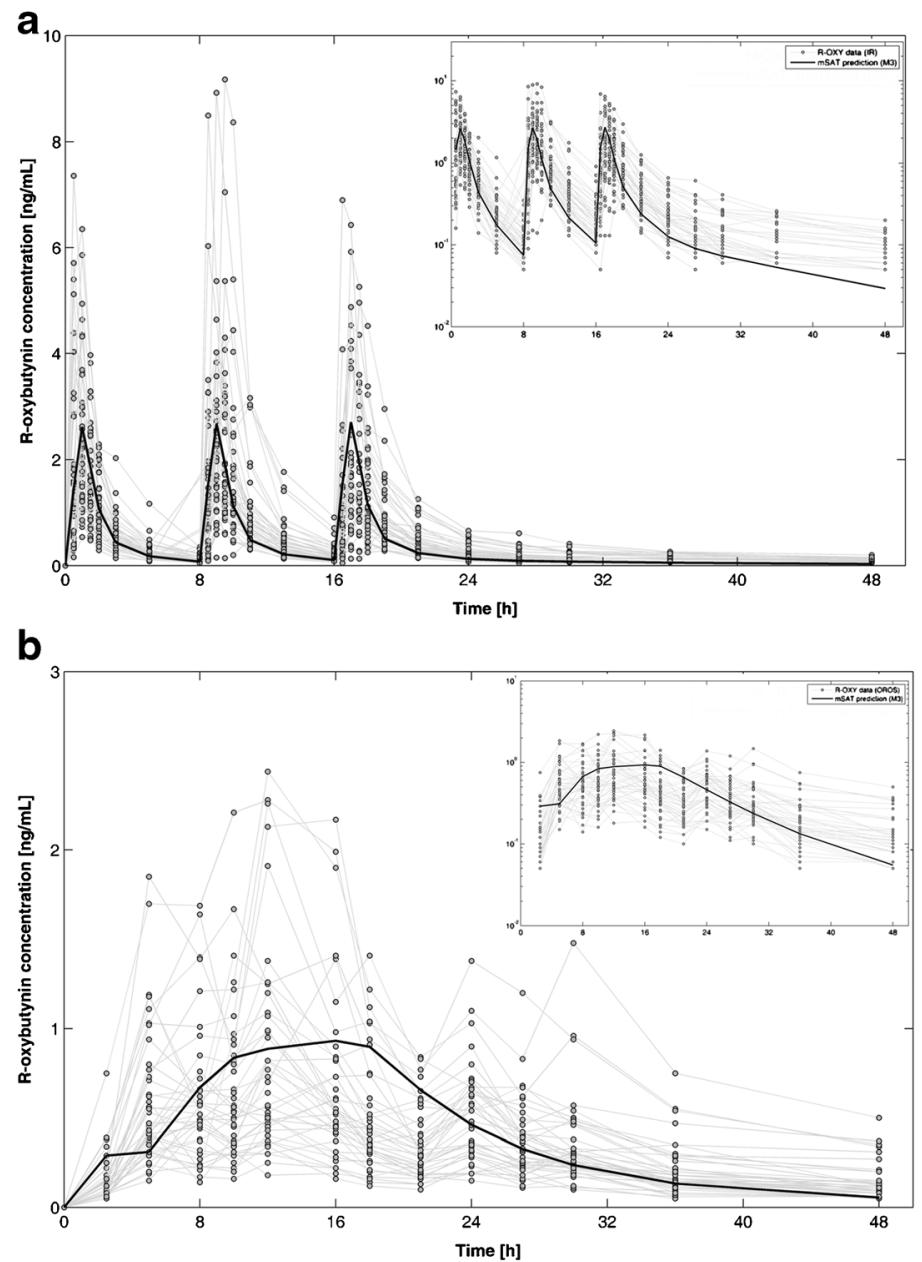

Fig. 4. mSAT model prediction of the pharmacokinetic of R-OXY after the administration of three 5-mg IR formulations (a) and one $10 \mathrm{mg}$ OROS ${ }^{\circledR}$ formulation (b). The solid black line represents the mSAT model prediction, whereas the solid grey circles and lines represent the individual observed clinical data (kindly provided by Janssen Pharmaceutica). The insert shows the same plot in the semi-logarithmic scale

description of the observed IV infusion data (30) and the model parameters were precisely estimated (Table III). It is worth mentioning that given the model structure and its local identifiability properties $(43,45,46)$, an exchange between the parameters, $Q_{\text {tissue, } 1}$ and $Q_{\text {tissue, },}$, and $V_{\text {tissue, } 1}$ and $V_{\text {tissue,2, can }}$ be made without affecting either fit or the input-output relationship of the model (Table III). The selected modelling approach required the fitting of both the intrinsic microsomal

Table IV. Summary of the mSAT Predicted $v s$. Observed Pharmacokinetic Parameters for OXY Formulations (IR and OROS $®$ )

\begin{tabular}{|c|c|c|c|c|c|c|c|c|c|c|c|c|c|}
\hline \multirow[t]{2}{*}{ Isomer } & \multirow[t]{2}{*}{ Formulation } & \multicolumn{4}{|c|}{ Observed values (mean $\pm \mathrm{SD}$ ) } & \multicolumn{8}{|c|}{ mSAT model predictions } \\
\hline & & $\begin{array}{l}A U C_{0-48} \\
{[\mathrm{ng} \times \mathrm{h} / \mathrm{mL}]}\end{array}$ & $\begin{array}{l}C_{\max } \\
{[\mathrm{ng} / \mathrm{mL}]}\end{array}$ & $\begin{array}{l}C_{10 h}{ }^{a} \\
{[\mathrm{ng} / \mathrm{mL}]}\end{array}$ & $F_{r e l}^{b, c}$ & $\begin{array}{l}A U C_{0-48} \\
{[\mathrm{ng} \times \mathrm{h} / \mathrm{mL}]}\end{array}$ & $\begin{array}{l}C_{\max } \\
{[\mathrm{ng} / \mathrm{mL}]}\end{array}$ & $\begin{array}{l}\mathrm{C}_{10 h}{ }^{a} \\
{[\mathrm{ng} / \mathrm{mL}]}\end{array}$ & $F_{r e l}^{c}$ & $F$ & $f_{a b s}$ & $F_{G}$ & $F_{H}$ \\
\hline \multirow[t]{2}{*}{$R-O X Y$} & IR & $21.7 \pm 13.0$ & $3.28 \pm 2.16$ & - & $\mathrm{n} / \mathrm{a}$ & 17.3 & 2.71 & - & $\mathrm{n} / \mathrm{a}$ & 0.078 & 1.00 & 0.13 & 0.61 \\
\hline & OROS $®$ & $18.6 \pm 10.5$ & $0.99 \pm 0.59$ & $0.65 \pm 0.42$ & $1.39 \pm 0.44$ & 19.5 & 0.93 & 0.84 & 1.70 & 0.13 & 0.28 & 0.80 & 0.58 \\
\hline \multirow[t]{2}{*}{$S-O X Y$} & IR & $31.6 \pm 15.8$ & $6.58 \pm 3.71$ & - & $\mathrm{n} / \mathrm{a}$ & 20.2 & 3.24 & - & $\mathrm{n} / \mathrm{a}$ & 0.075 & 1.00 & 0.10 & 0.71 \\
\hline & OROS® & $34.4 \pm 17.3$ & $1.84 \pm 0.97$ & $1.18 \pm 0.71$ & $1.72 \pm 0.49$ & 27.4 & 1.32 & 1.19 & 2.04 & 0.15 & 0.28 & 0.79 & 0.69 \\
\hline
\end{tabular}

$S D$ standard deviation

${ }^{a}$ Concentration at $10 \mathrm{~h}$

${ }^{b}$ The observed $F_{\text {rel }}$ is the mean of the individually calculated $F_{\text {rel }}$

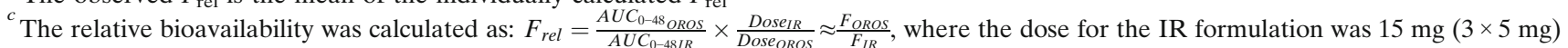
and $10 \mathrm{mg}$ for the OROS formulation 
a

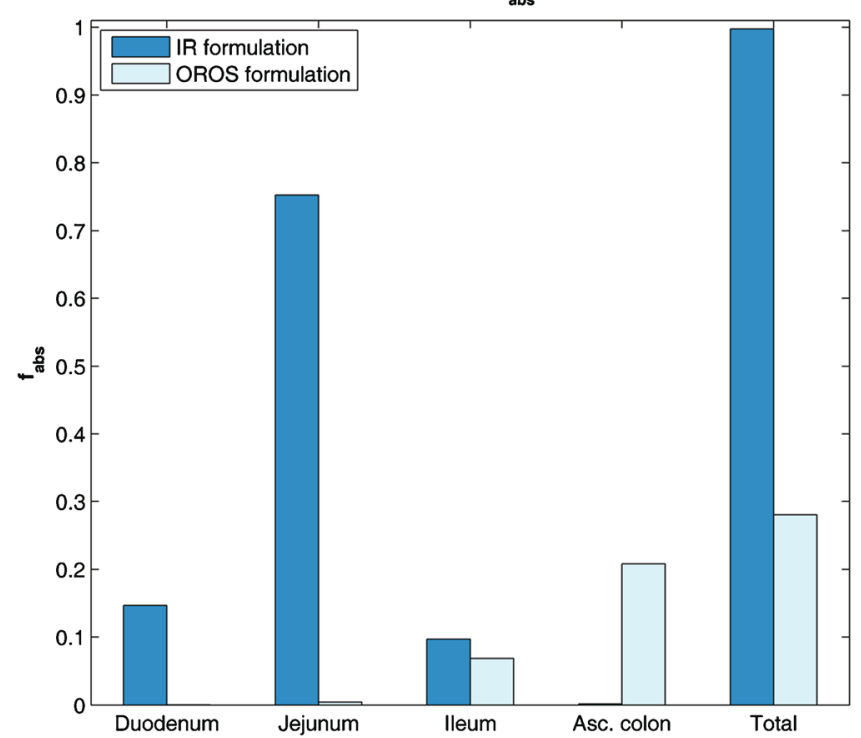

b

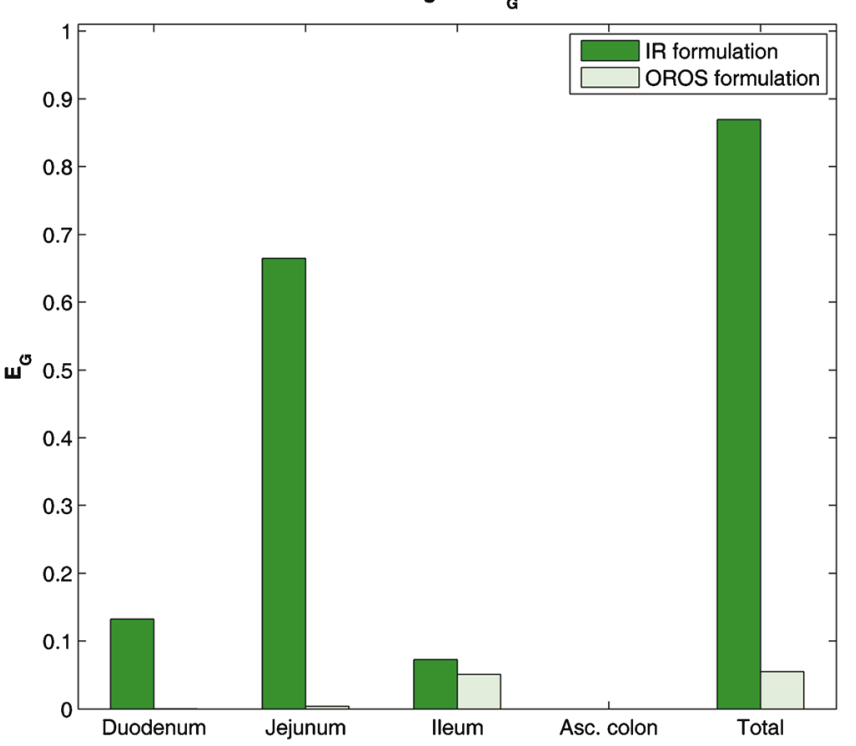

Fig. 5. mSAT predicted segmental and oral bioavailability fractions for R-OXY IR and OROS ${ }^{\circledR}$ formulations. a Predicted $f_{\text {abs; }}$; dark blue bars represent the IR formulation and the light blue bars represent the OROS ${ }^{\circledR}$ formulation. b Predicted fraction of the administered dose metabolized in the intestinal segments $\left(E_{G}\right)$; dark green bars represent the IR formulation and the light green bars represent the OROS ${ }^{\circ}$ formulation

clearance and an empirical $K_{\mathrm{pu}}$ value. The former could have been informed purely from the reported in vitro data, where the unbound in vitro formation $\mathrm{CL}_{\text {int }}$ in HLM has been reported to be 225 and $278 \mu \mathrm{L} / \mathrm{min} / \mathrm{mg}$ for R-OXY and S-OXY, respectively (75). However, there were indications that suggested that the use of such in vitro value would have led to under-predictions in both the systemic clearance and first-pass metabolism of $\mathrm{OXY}$ (21). This underestimation has been previously reported in the literature, particularly for highly cleared and highly proteinbound substrates similar to OXY $(86,87)$. For these reasons, fitting the microsomal clearance to the IV infusion data seemed to be a reasonable choice. This was supported by the estimated

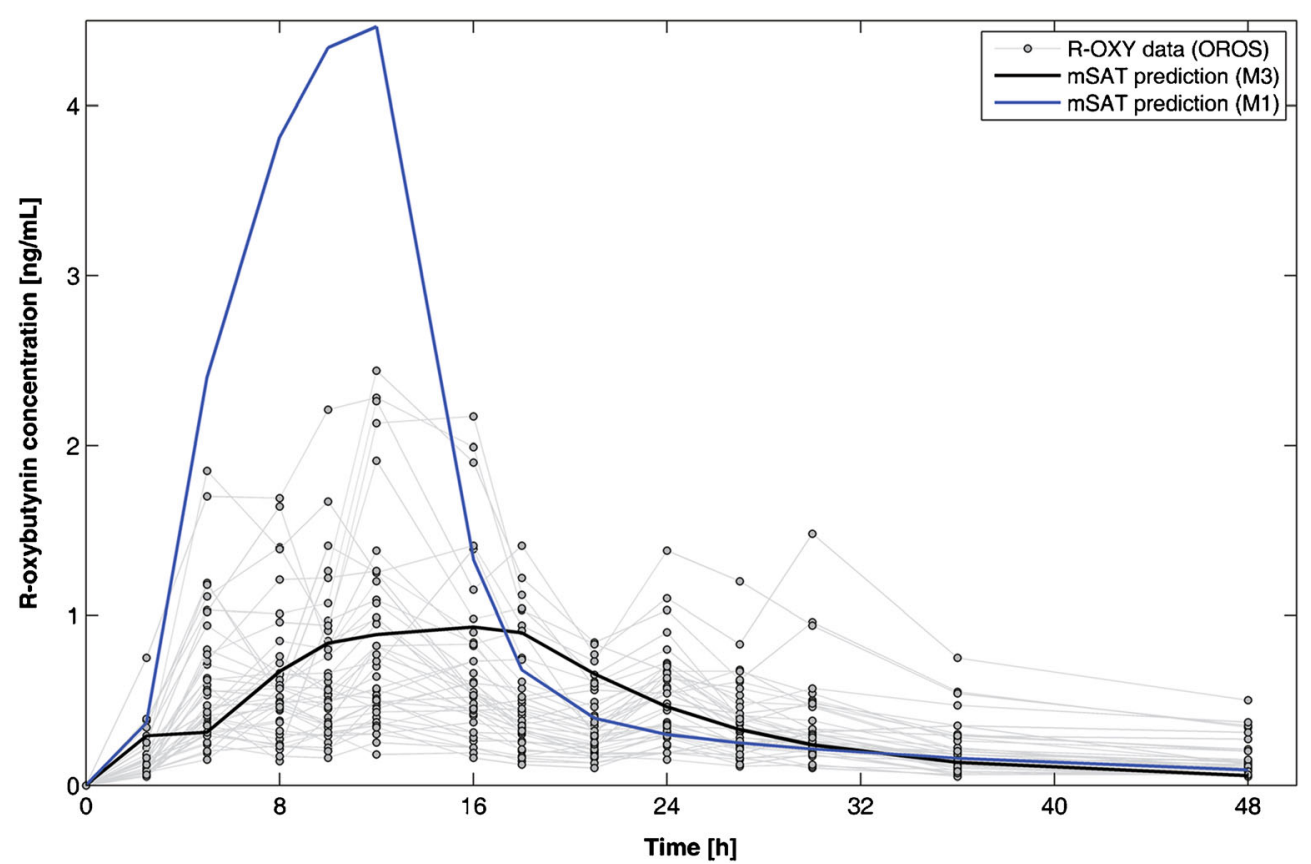

Fig. 6. mSAT model prediction of the pharmacokinetic of $R-O X Y$ after the administration of a 10-mg OROS ${ }^{\circledR}$ formulation using two different permeability approaches. The solid black line represents the mSAT model prediction using segment-dependent permeability (M3 method), whereas the solid blue line is the model prediction using the same $P_{\text {eff }}$ value in all the intestinal segments (M1 method) (26). Circles and lines represent the individual observed clinical data (kindly provided by Janssen Pharmaceutica) 
$\mathrm{CL}_{\text {int }}$ of $3944 \mu \mathrm{L} / \mathrm{min} / \mathrm{mg}$ for racemic OXY (Table III). However, this estimate assumes that only the CYP-mediated metabolism was responsible for OXY's elimination, which might not be necessarily true as there is evidence of the formation of an inactive metabolite, 2-cyclohexyl-2-phenylglycolic acid (CPGA), which is mediated by carboxylesterases (mainly CES1) that can be found in both predominantly in the liver and in the intestinal wall to a smaller extent $(88,89)$. Nevertheless, the CPGA formation was assumed to contribute minimally to OXY's overall elimination, given that the reported in vitro CPGA formation $\mathrm{CL}_{\text {int }}$ in HLM was $5.9 \mu \mathrm{L} / \mathrm{min} / \mathrm{mg}$, a value considerably smaller than the reported formation $\mathrm{CL}_{\text {int }}$ of OXY's main metabolite, NDEO $(75,89)$.

The fitted $K_{\mathrm{pu}}$ value was assumed to be the same for all the empirical tissues. This assumption was mainly based on model structural identifiability grounds that otherwise would have deemed the model as unidentifiable $(43,44)$. The decision to estimate a $K_{\mathrm{pu}}$ value, instead of directly estimating the $K_{b}$ needed in the model equations, was made to allow for the prediction of the pharmacokinetics of OXY enantiomers. While there is a difference in plasma binding between the two enantiomers, we have assumed that the $K_{\mathrm{pu}}$ value was the same for both the racemic OXY and its enantiomers $(R$ and $S$-OXY). This assumption was based on the fact that OXY, a strong base $(\mathrm{pKa}>7)$, is predominantly bound to $\alpha_{1^{-}}$ acidglycoprotein (AGP), which is mainly located in the circulating plasma. Thus, the impact of OXY's binding to AGP within tissues was assumed to be minimal $(82,90)$. Consequently, differences in OXY's volume of distribution can be mainly attributed to plasma protein-binding differences between the enantiomers (and racemic mixture), rather than to tissue binding $(75,82,90)$. These differences were accommodated in the disposition model by using the enantiomer-specific $f_{u p}$ value in the calculation of the $K_{b}$, which in turn affects the volume of distribution (Eq. 5). The latter also highlights the usefulness of the chosen hybridPBPK model structure employed in this work, as this extrapolation could have not been possible when using a traditional three-compartment model to describe OXY's disposition.

The second step in the modelling approach involved the expansion of the mSAT model for the mechanistic prediction of OXY oral bioavailability in a purely prospective manner. As previously described in the "Materials and Methods" section, the model was expanded by incorporating mechanistic equations for the prediction of the most relevant absorption processes using MATLAB: transit, release, dissolution, permeation and intestinal metabolism. Using the expanded mSAT model, the predictions of the oral pharmacokinetic profile of the racemic OXY after the administration of three $5 \mathrm{mg}$ IR tables in the reference individual were in good agreement with the mean observed data (Fig. 3). Similarly, the predicted absolute bioavailability of the racemic OXY was within $5 \%$ of the reported mean value of $6.2 \%$ for the IR tablets (the oral solution was shown to be bioequivalent with the tablets) (30). Since OXY's disposition was already accounted by the model in the previous step, the predictions of oral bioavailability were mainly attributed to the mechanistic nature of the mSAT model and the use of the appropriate system-related and drug-specific parameters for such predictions (Tables I and II); the latter provided further support for the use of this model for mechanistic oral absorption predictions (26). Since OXY belongs to Class 1 within the BCS (highly permeable and soluble), there were no major difficulties in terms of the prediction of the dissolution and permeation processes for the IR formulation within the mSAT model (21). These processes were not considered to be the rate-limiting step for OXY's absorption (30). In contrast, prediction of OXY's first-pass metabolism was considered the key step for the bioavailability predictions of OXY's IR formulation. Judging by the outcome of the bioavailability predictions, the expanded mSAT model did a reasonable job for such predictions. The latter also highlights the importance of having good disposition data available for the purpose of judging mechanistic bioavailability predictions, particularly due to the possible confounding issues that can arise from the use of the oral data to calibrate some of the absorption parameters in the model, particularly when the predictions are not in agreement with the observed clinical data. The latter might lead to biased estimates of the absorption parameters due to the fact that the disposition parameters were biased in the first instance $(42,91)$.

Once the ability of the mSAT model to prospectively predict the oral pharmacokinetic profile was established, the third and final step of the modelling approach was the mechanistic investigation of the relative bioavailability between OXY's IR and OROS ${ }^{\circledR}$ formulations. The pharmacokinetic profiles of both formulations were successfully predicted by the model for the reference individual as shown in Fig. 4 and summarized in Table IV. However, as seen in Fig. 4, there is a large interindividual variability (IIV) in the observed pharmacokinetic profiles. This IIV was not captured by the mSAT model as it can only provide predictions for the "typical individual". This is in contrast to available software packages that can include such variability in the model predictions such as SimCYP® and PK-Sim $®$.

In terms of relative bioavailability, the model predictions were consistent with the observed trend of higher exposure when using the OROS® formulation compared to the IR tablets (Table IV) (28,31). However, the model slightly overestimated the magnitude of the relative bioavailability of the OROS ${ }^{\circ}$ formulation, mainly due to a $40 \%$ underestimation of the exposure of the IR formulations (particularly for the S-OXY). This underestimation could be due to the assumptions made with regard to the intrinsic clearances of each isomer in the model predictions, such as the use of the in vitro $\mathrm{R} / \mathrm{S}_{\mathrm{CLint} \text {,ratio }}$ to derive the isomer-specific $\mathrm{CL}_{\text {int(u) }}$ employed in the mSAT model. However, considering that these predictions were based purely on available literature data and no further optimization were made in any of absorption model parameters, this bias was considered acceptable.

From a mechanistic perspective, the model predictions with regard to the bioavailability fractions were consistent with the previous multi-factorial simulation study (21). The predicted $f_{a b s}$ of R-OXY and S-OXY were close to the unity, in agreement with the mass balance studies suggesting the complete absorption of the racemic mixture (30). Due to the use of the differential permeability approach employed in the model, the segmental contribution to the overall absorption can be estimated for the different formulations (26). Most of the drug 
content from the IR formulation was predicted to be absorbed in the upper GI segments (Fig. 5a). Similarly, predictions can be made with regard to the fate of the drug in the enterocyte compartments (Fig. 5b) where most of the drug content was expected to be eliminated by the CYP enzymes located in the upper regions of the GI segments (21-24). As shown in Table IV, the predicted $F_{G}$ of the IR formulation was approximately 0.13 for both isomers. This value was in close agreement with the observed $F_{G}$ of 0.11 to 0.14 , calculated from the reported absolute bioavailability and the in vivo clearance using the standard formulae $(30,92)$. The model predicted an $F_{H}$ close to 0.61 and 0.71 for IR formulation of R-OXY and S-OXY, respectively. These values were slightly higher than the estimated $F_{H}$ between 0.44 and 0.58 for the racemic mixture $(30,92)$. The segmented structure of the mSAT model was necessary for the bioavailability predictions of the OXY's OROS® formulation, particularly when the model structure was combined with the regional permeability approach (M3) (26). Otherwise, the absorption of the OROS ${ }^{\circledR}$ formulation would have been considerably overestimated when using the same $P_{\text {eff }}$ value for all the segments of the mSAT model, as shown in Fig. 6. This highlights the importance of accounting for the segmental permeability difference in the PBPK framework $(26,73,93)$.

Even though there is no available clinical data regarding to the regional absorption and/or intestinal first-pass metabolism of the OXY's OROS $®$ formulations. The model outcome can be used to explain the mechanism proposed for the higher relative bioavailability of OXY's OROS ${ }^{\circledR}$ formulation. It was clear from Fig. 5 and Table IV that the $f_{a b s}$ for the OROS ${ }$ formulation was considerably reduced compared to the IR formulation. However, the predicted $F_{G}$ was almost eight times higher in the OROS® formulation compared to the IR. Since the predicted $F_{H}$ remained almost the same for both formulations (IR and OROS $®$ ), the model provided strong support for the hypothesis that the main factor responsible for the higher relative bioavailability observed for OXY's OROS® formulation was an increased intestinal availability $(21,28)$. This increased availability was mainly due to release of the majority of the drug content from the OROS $®$ formulation in the distal regions of the GI tract, where the abundance of CYP is reduced compared to the upper GI tract (22-24). This outcome not only corroborates the findings from previous work but also can be seen as a further support to the fact that there is an interesting interplay between absorption and metabolism along the GI that can be explored in formulation development. This phenomenon could be of importance for substrates similar to OXY, where a MR release formulation can be developed to either increase or maintain exposure levels observed with the IR counterparts.

One of the main limitations of this study was the lack of predictions including variability and uncertainty. This variability might be incorporated in the model through the model parameters either from literature sources or estimated from data, and it can be of importance to understand the possible differences in OXY's $F_{G}$ to its full extent. Another important aspect that was not accounted for in this work was the fate of OXY's main metabolite, DEOB. This metabolite has clinical implications as it has been associated with the occurrence of OXY's side effects $(28,31,32)$. However, there was a paucity of data available in the literature regarding the metabolite and did not allow its incorporation in the current model using a "bottom-up" approach. Another aspect that was not considered in this work was the impact that OXY's anticholinergic activity could have had on gastric emptying and intestinal transit time. This was mainly due to the lack of a pharmacodynamic link for its implementation in the model. However, we did not expect differences in terms of relative bioavailability predictions as this effect is related to OXY's therapeutic activity (i.e. smooth muscle relaxant) which has been shown to be similar between the two formulations (32).

Finally, the results highlighted the usefulness of the newly proposed mSAT model for oral pharmacokinetic predictions. However, these result should be considered carefully as more compounds need to be tested with this particular model.

\section{CONCLUSION}

A newly proposed mechanistic absorption model was expanded and employed for the bottom-up predictions of oral bioavailability of oxybutynin IR and OROS $®$ formulations. The new model was able to capture the bioavailability differences observed between OXY formulations, where the OROS $®$ formulation displayed higher relative bioavailability than its IR counterpart. The model predictions suggest that this higher bioavailability was mainly due to an increased intestinal availability $\left(F_{G}\right)$ product of the decreased intestinal first-pass metabolism in the distal regions of the GI tract, where the abundance of the CYP enzymes is decreased.

\section{ACKNOWLEDGMENTS}

A.O-M. is recipient of a Ph.D. grant awarded by CONICYT Chile, Chilean Ministry of Education and a President's Doctoral Scholar Award from The University of Manchester. The authors would like to acknowledge Janssen Pharmaceutica for providing the observed clinical data for the relative bioavailability between oxybutynin's IR and OROS ${ }^{\circledR}$ formulation, as well as Drs. Luca Marciani (University of Nottingham), Deana Mudie (University of Michigan), Prof. Wener Weitschies and Michael Grimm (University of Greifswald) for providing insight on the luminal free water data employed in the development of the fluid dynamics model implemented in the mSAT model. Finally, we would acknowledge the fruitful comments and discussions made with members of the Centre for Applied Pharmacokinetic Research (CAPKR) of The University of Manchester, particularly Thierry Wendling, Nikos Tsamandouras and Aleksandra Galetin. This project is an in-kind contribution from the University of Manchester to the IMI Oral Biopharmaceutics Tools (OrBiTo) project (http:// www.imi.europa.eu/content/orbito).

Open Access This article is distributed under the terms of the Creative Commons Attribution 4.0 International License (http://creativecommons.org/licenses/by/4.0/), which permits unrestricted use, distribution, and reproduction in any medium, provided you give appropriate credit to the original author(s) and the source, provide a link to the Creative Commons license, and indicate if changes were made. 


\section{REFERENCES}

1. Rowland M, Peck C, Tucker G. Physiologically-based pharmacokinetics in drug development and regulatory science. Annu Rev Pharmacol Toxicol. 2011;51:45-73. doi:10.1146/annurevpharmtox-010510-100540.

2. Zhao P, Rowland M, Huang SM. Best practice in the use of physiologically based pharmacokinetic modeling and simulation to address clinical pharmacology regulatory questions. Clin Pharmacol Ther. 2012;92(1):17-20. http://www.nature.com/clpt/ journal/v92/n1/suppinfo/clpt201268s1.html.

3. Zhao P, Zhang L, Grillo JA, Liu Q, Bullock JM, Moon YJ, et al. Applications of Physiologically Based Pharmacokinetic (PBPK) modeling and simulation during regulatory review. Clin Pharmacol Ther. 2011;89(2):259-67.

4. Jones HM, Chen Y, Gibson C, Heimbach T, Parrott N, Peters $\mathrm{SA}$, et al. Physiologically based pharmacokinetic modeling in drug discovery and development: a pharmaceutical industry perspective. Clin Pharmacol Ther. 2015;97(3):247-62. doi:10.1002/cpt.37.

5. Rostami-Hodjegan A, Tamai I, Pang KS. Physiologically based pharmacokinetic (PBPK) modeling: it is here to stay! Biopharm Drug Dispos. 2012;33(2):47-50. doi:10.1002/bdd.1776.

6. Rostami-Hodjegan A. Physiologically based pharmacokinetics joined with in vitro-in vivo extrapolation of ADME: a marriage under the arch of systems pharmacology. Clin Pharmacol Ther. 2012;92(1):50-61. doi:10.1038/clpt.2012.65.

7. Jamei M, Marciniak S, Feng K, Barnett A, Tucker G, RostamiHodjegan A. The Simcyp population-based ADME simulator. Expert Opin Drug Metab Toxicol. 2009;5(2):211-23. doi:10.1517/ 17425250802691074.

8. Agoram B, Woltosz WS, Bolger MB. Predicting the impact of physiological and biochemical processes on oral drug bioavailability. Adv Drug Deliv Rev. 2001;50 Suppl 1:S41-67. doi:10.1016/S0169-409X(01)00179-X.

9. Thelen K, Coboeken K, Willmann S, Burghaus R, Dressman JB, Lippert J. Evolution of a detailed physiological model to simulate the gastrointestinal transit and absorption process in humans, part 1: oral solutions. J Pharm Sci. 2011;100(12):532445. doi:10.1002/jps.22726.

10. Willmann S, Schmitt W, Keldenich J, Lippert J, Dressman JB. A physiological model for the estimation of the fraction dose absorbed in humans. J Med Chem. 2004;47(16):4022-31. doi:10.1021/jm030999b.

11. Gertz M, Houston JB, Galetin A. Physiologically based pharmacokinetic modeling of intestinal first-pass metabolism of CYP3A substrates with high intestinal extraction. Drug Metab Dispos. 2011;39(9):1633-42. doi:10.1124/dmd.111.039248.

12. Chen E, Tai G, Ellens H. The importance of villous physiology and morphology in mechanistic physiologically-based pharmacokinetic models. Pharm Res. 2014;31(2):305-21. doi:10.1007/ s11095-013-1161-x.

13. Sjogren E, Westergren J, Grant I, Hanisch G, Lindfors L, Lennernas $\mathrm{H}$, et al. In silico predictions of gastrointestinal drug absorption in pharmaceutical product development: application of the mechanistic absorption model GI-Sim. Eur J Pharm Sci. 2013;49(4):679-98. doi:10.1016/j.ejps.2013.05.019.

14. Cong D, Doherty M, Pang KS. A new physiologically based, segregated-flow model to explain route-dependent intestinal metabolism. Drug Metab Dispos. 2000;28(2):224-35.

15. Darwich AS, Neuhoff S, Jamei M, Rostami-Hodjegan A. Interplay of metabolism and transport in determining oral drug absorption and gut wall metabolism: a simulation assessment using the "Advanced Dissolution, Absorption, Metabolism (ADAM)" model. Curr Drug Metab. 2010;11(9):716-29.

16. Martinez MN, Amidon GL. A mechanistic approach to understanding the factors affecting drug absorption: a review of fundamentals. J Clin Pharmacol. 2002;42(6):620-43.

17. Poggesi I, Snoeys J, Van Peer A. The successes and failures of physiologically based pharmacokinetic modeling: there is room for improvement. Expert Opin Drug Metab Toxicol. 2014;10(5): 631-5. doi:10.1517/17425255.2014.888058.

18. Poulin P, Jones RDO, Jones HM, Gibson CR, Rowland M, Chien JY, et al. PHRMA CPCDC initiative on predictive models of human pharmacokinetics, part 5: prediction of plasma concentration-time profiles in human by using the physiologically-based pharmacokinetic modeling approach. J Pharm Sci. 2011;100(10):4127-57. doi:10.1002/jps.22550.

19. Parrott N, Paquereau N, Coassolo P, Lave T. An evaluation of the utility of physiologically based models of pharmacokinetics in early drug discovery. J Pharm Sci. 2005;94(10):2327-43. doi:10.1002/jps.20419.

20. Lennernas H, Aarons L, Augustijns P, Beato S, Bolger M, Box $\mathrm{K}$, et al. Oral biopharmaceutics tools - time for a new initiative an introduction to the IMI project OrBiTo. Eur J Pharm Sci. 2014;57:292-9. doi:10.1016/j.ejps.2013.10.012.

21. Olivares-Morales A, Kamiyama Y, Darwich AS, Aarons L, Rostami-Hodjegan A. Analysis of the impact of controlled release formulations on oral drug absorption, gut wall metabolism and relative bioavailability of CYP3A substrates using a physiologically-based pharmacokinetic model. Eur J Pharm Sci. 2015;67:32-44. doi:10.1016/j.ejps.2014.10.018.

22. Paine MF, Khalighi M, Fisher JM, Shen DD, Kunze KL, Marsh $\mathrm{CL}$, et al. Characterization of interintestinal and intraintestinal variations in human CYP3A-dependent metabolism. J Pharmacol Exp Ther. 1997;283(3):1552-62.

23. Kolars JC, Lown KS, Schmiedlin-Ren P, Ghosh M, Fang C, Wrighton SA, et al. CYP3A gene expression in human gut epithelium. Pharmacogenetics. 1994;4(5):247-59.

24. Bruyere A, Decleves X, Bouzom F, Ball K, Marques C, Treton $\mathrm{X}$, et al. Effect of variations in the amounts of P-glycoprotein (ABCB1), BCRP (ABCG2) and CYP3A4 along the human small intestine on PBPK models for predicting intestinal first pass. Mol Pharm. 2010;7(5):1596-607. doi:10.1021/mp100015x.

25. Tannergren C, Bergendal A, Lennernas H, Abrahamsson B. Toward an increased understanding of the barriers to colonic drug absorption in humans: implications for early controlled release candidate assessment. Mol Pharm. 2009;6(1):60-73. doi:10.1021/mp800261a.

26. Olivares-Morales A, Lennernas H, Aarons L, Rostami-Hodjegan A. Translating human effective jejunal intestinal permeability to surface-dependent intrinsic permeability: a pragmatic method for a more mechanistic prediction of regional oral drug absorption. AAPS J. 2015;17(5):1177-92. doi:10.1208/s12248-015-9758-0.

27. Helander HF, Fandriks L. Surface area of the digestive tract-revisited. Scand J Gastroenterol. 2014;49(6):681-9. doi:10.3109/00365521.2014.898326.

28. Gupta SK, Sathyan G. Pharmacokinetics of an oral once-a-day controlled-release oxybutynin formulation compared with immediate-release oxybutynin. J Clin Pharmacol. 1999;39(3):289-96.

29. Yaich M, Popon M, Medard Y, Aigrain EJ. In-vitro cytochrome P450 dependent metabolism of oxybutynin to N-deethyloxybutynin in humans. Pharmacogenetics. 1998;8(5):449-51.

30. Douchamps J, Derenne F, Stockis A, Gangji D, Juvent M, Herchuelz A. The pharmacokinetics of oxybutynin in man. Eur J Clin Pharmacol. 1988;35(5):515-20. doi:10.1007/BF00558247.

31. Sathyan G, Chancellor MB, Gupta SK. Effect of OROS ${ }^{\circledR}$ controlled-release delivery on the pharmacokinetics and pharmacodynamics of oxybutynin chloride. Br J Clin Pharmacol. 2001;52(4):409-17. doi:10.1046/j.0306-5251.2001.01463.x.

32. Gupta SK, Sathyan G, Lindemulder EA, Ho P-L, Sheiner LB, Aarons L. Quantitative characterization of therapeutic index: application of mixed-effects modeling to evaluate oxybutynin dose-efficacy and dose-side effect relationships. Clin Pharmacol Ther. 1999;65(6):672-84.

33. Cao Y, Jusko WJ. Applications of minimal physiologically-based pharmacokinetic models. J Pharmacokinet Pharmacodyn. 2012;39(6):711-23. doi:10.1007/s10928-012-9280-2.

34. Nestorov IA, Aarons LJ, Arundel PA, Rowland M. Lumping of whole-body physiologically based pharmacokinetic models. J Pharmacokinet Biopharm. 1998;26(1):21-46. doi:10.1023/ A:1023272707390.

35. Dokoumetzidis A, Aarons L. Proper lumping in systems biology models. IET Syst Biol. 2009;3(1):40-51. doi:10.1049/ietsyb:20070055.

36. Dokoumetzidis A, Aarons L. A method for robust model order reduction in pharmacokinetics. J Pharmacokinet Pharmacodyn. 2009;36(6):613-28. doi:10.1007/s10928-009-9141-9. 
37. Valentin J. Basic anatomical and physiological data for use in radiological protection: reference values. Ann ICRP. 2002;32(34):1-277. doi:10.1016/s0146-6453(03)00002-2.

38. Williams LR, Leggett RW. Reference values for resting blood flow to organs of man. Clin Phys Physiol Meas. 1989;10(3):187217.

39. Matheson PJ, Wilson MA, Garrison RN. Regulation of intestinal blood flow. J Surg Res. 2000;93(1):182-96. doi:10.1006/ jsre.2000.5862.

40. Howgate EM, Rowland Yeo K, Proctor NJ, Tucker GT, Rostami-Hodjegan A. Prediction of in vivo drug clearance from in vitro data. I: impact of inter-individual variability. Xenobiotica. 2006;36(6):473-97. doi:10.1080/00498250600683197.

41. Rodgers T, Leahy D, Rowland M. Physiologically based pharmacokinetic modeling 1: predicting the tissue distribution of moderate-to-strong bases. J Pharm Sci. 2005;94(6):1259-76. doi:10.1002/jps.20322.

42. Tsamandouras N, Wendling T, Rostami-Hodjegan A, Galetin A, Aarons L. Incorporation of stochastic variability in mechanistic population pharmacokinetic models: handling the physiological constraints using normal transformations. J Pharmacokinet Pharmacodyn. 2015;42(4):349-73. doi:10.1007/s10928-015-9418-0.

43. Jacquez JA, Perry T. Parameter estimation: local identifiability of parameters. Am J Phys. 1990;258(4 Pt 1):E727-36.

44. Godfrey KR, Fitch WR. The deterministic identifiability of nonlinear pharmacokinetic models. J Pharmacokinet Biopharm. 1984;12(2):177-91.

45. Karlsson J, Anguelova M, Jirstrand M, editors. An efficient method for structural identiability analysis of large dynamic systems. 16th IFAC Symposium on System Identification; 2012.

46. Anguelova M, Karlsson J, Jirstrand M. Minimal output sets for identifiability. Math Biosci. 2012;239(1):139-53. doi:10.1016/ j.mbs.2012.04.005.

47. Bauer R. NONMEM users guide: introduction to NONMEM 7.3.0. Hanover: ICON Development Solutions; 2013.

48. Langdon G, Gueorguieva I, Aarons L, Karlsson M. Linking preclinical and clinical whole-body physiologically based pharmacokinetic models with prior distributions in NONMEM. Eur J Clin Pharmacol. 2007;63(5):485-98. doi:10.1007/s00228-007-0264-x.

49. Carroll RJ, Ruppert D. Transformation and weighting in regression. Monographs on Statistics \& Applied Probability, vol. 30. New York: Chapman \& Hall/CRC Press; 1988.

50. Yu LX, Amidon GL. A compartmental absorption and transit model for estimating oral drug absorption. Int $\mathrm{J}$ Pharm. 1999;186(2):119-25. doi:10.1016/S0378-5173(99)00147-7.

51. Yu LX, Lipka E, Crison JR, Amidon GL. Transport approaches to the biopharmaceutical design of oral drug delivery systems: prediction of intestinal absorption. Adv Drug Deliv Rev. 1996;19(3):359-76. doi:10.1016/0169-409X(96)00009-9.

52. Yu LX, Crison JR, Amidon GL. Compartmental transit and dispersion model analysis of small intestinal transit flow in humans. Int J Pharm. 1996;140(1):111-8. doi:10.1016/03785173(96)04592-9.

53. Jamei M, Turner D, Yang J, Neuhoff S, Polak S, RostamiHodjegan A, et al. Population-based mechanistic prediction of oral drug absorption. AAPS J. 2009;11(2):225-37. doi:10.1208/ s12248-009-9099-y.

54. Amidon GL, Lennernas H, Shah VP, Crison JR. A theoretical basis for a biopharmaceutic drug classification: the correlation of in vitro drug product dissolution and in vivo bioavailability. Pharm Res. 1995;12(3):413-20.

55. International Commission on Radiological Protection. Report of the task group on reference man. New York: Pergamon Press; 1975.

56. Yu LX, Amidon GL. Saturable small intestinal drug absorption in humans: modeling and interpretation of cefatrizine data. Eur $\mathbf{J}$ Pharm Biopharm. 1998;45(2):199-203. doi:10.1016/S09396411(97)00088-X.

57. Read NW, Al-Janabi MN, Holgate AM, Barber DC, Edwards CA. Simultaneous measurement of gastric emptying, small bowel residence and colonic filling of a solid meal by the use of the gamma camera. Gut. 1986;27(3):300-8.

58. Davis SS, Hardy JG, Fara JW. Transit of pharmaceutical dosage forms through the small-intestine. Gut. 1986;27(8):886-92. doi:10.1136/Gut.27.8.886.
59. Hénin E, Bergstrand M, Standing J, Karlsson M. A mechanismbased approach for absorption modeling: the Gastro-Intestinal Transit Time (GITT) model. AAPS J. 2012;14(2):155-63. doi:10.1208/s12248-012-9324-y.

60. Bouchoucha M, Devroede G, Dorval E, Faye A, Arhan P, Arsac M. Different segmental transit times in patients with irritable bowel syndrome and "normal" colonic transit time: is there a correlation with symptoms? Tech Coloproctol. 2006;10(4):28796. doi:10.1007/s10151-006-0295-9.

61. Bouchoucha M, Thomas SR. Error analysis of classic colonic transit time estimates. Am J Physiol Gastrointest Liver Physiol. 2000;279(3):G520-7.

62. Dokoumetzidis A, Macheras P. A century of dissolution research: from Noyes and Whitney to the biopharmaceutics classification system. Int J Pharm. 2006;321(1-2):1-11. doi:10.1016/j.ijpharm.2006.07.011.

63. Wang J, Flanagan DR. General solution for diffusion-controlled dissolution of spherical particles. 1. Theory. J Pharm Sci. 1999;88(7):731-8. doi:10.1021/js980236p.

64. Johnson KC. Comparison of methods for predicting dissolution and the theoretical implications of particle-size-dependent solubility. J Pharm Sci. 2012;101(2):681-9. doi:10.1002/jps.22778.

65. Sugano K. Theoretical comparison of hydrodynamic diffusion layer models used for dissolution simulation in drug discovery and development. Int J Pharm. 2008;363(1-2):73-7. doi:10.1016/ j.ijpharm.2008.07.002.

66. Hintz RJ, Johnson KC. The effect of particle size distribution on dissolution rate and oral absorption. Int J Pharm. 1989;51(1):917. doi:10.1016/0378-5173(89)90069-0.

67. Okazaki A, Mano T, Sugano K. Theoretical dissolution model of poly-disperse drug particles in biorelevant media. J Pharm Sci. 2008;97(5):1843-52. doi:10.1002/jps.21070.

68. Sugano K. Computational oral absorption simulation for lowsolubility compounds. Chem Biodivers. 2009;6(11):2014-29. doi:10.1002/cbdv.200900101.

69. Johnson K. Dissolution and absorption modeling: model expansion to simulate the effects of precipitation, water absorption, longitudinally changing intestinal permeability, and controlled release on drug absorption. Drug Dev Ind Pharm. 2003;29(8):833-42. doi:10.1081/DDC-120024179.

70. Avdeef A. Solubility of sparingly-soluble ionizable drugs. Adv Drug Deliv Rev. 2007;59(7):568-90. doi:10.1016/ j.addr.2007.05.008.

71. Mudie DM, Murray K, Hoad CL, Pritchard SE, Garnett MC, Amidon GL, et al. Quantification of gastrointestinal liquid volumes and distribution following a $240 \mathrm{~mL}$ dose of water in the fasted state. Mol Pharm. 2014;11(9):3039-47. doi:10.1021/ mp500210c.

72. Sugano K. Estimation of effective intestinal membrane permeability considering bile micelle solubilisation. Int $\mathrm{J}$ Pharm. 2009;368(1-2):116-22. doi:10.1016/j.ijpharm. 2008.10.001.

73. Lennernas H. Human in vivo regional intestinal permeability: importance for pharmaceutical drug development. Mol Pharm. 2014;11(1):12-23. doi:10.1021/mp4003392.

74. Zur M, Gasparini M, Wolk O, Amidon GL, Dahan A. The low/ high BCS permeability class boundary: physicochemical comparison of metoprolol and labetalol. Mol Pharm. 2014;11(5):170714. doi:10.1021/mp500152y.

75. Mizushima H, Takanaka K, Abe K, Fukazawa I, Ishizuka H. Stereoselective pharmacokinetics of oxybutynin and $\mathrm{N}$ desethyloxybutynin in vitro and in vivo. Xenobiotica. 2007;37(1):59-73. doi:10.1080/00498250600976088.

76. Rowland Yeo K, Rostami-Hodjegan A, Tucker GT. Abundance of Cytochromes P450 in human liver: a meta-analysis. Br J Clin Pharmacol. 2004;57:687-8.

77. Sjogren E, Abrahamsson B, Augustijns P, Becker D, Bolger MB, Brewster $\mathrm{M}$, et al. In vivo methods for drug absorption comparative physiologies, model selection, correlations with in vitro methods (IVIVC), and applications for formulation/ API/excipient characterization including food effects. Eur J Pharm Sci. 2014;57:99-151. doi:10.1016/j.ejps.2014.02.010.

78. Paine MF, Hart HL, Ludington SS, Haining RL, Rettie AE, Zeldin DC. The human intestinal cytochrome P450 "pie". Drug Metab Dispos. 2006;34(5):880-6. doi:10.1124/dmd.105.008672. 
79. Yang J, Tucker GT, Rostami-Hodjegan A. Cytochrome P450 3A expression and activity in the human small intestine. Clin Pharmacol Ther. 2004;76(4):391. doi:10.1016/j.clpt.2004.07.001.

80. Yang J, Jamei M, Yeo KR, Tucker GT, Rostami-Hodjegan A. Prediction of intestinal first-pass drug metabolism. Curr Drug Metab. 2007;8(7):676-84.

81. Pitsiu M, Sathyan G, Gupta S, Verotta D. A semiparametric deconvolution model to establish in vivo-in vitro correlation applied to OROS oxybutynin. J Pharm Sci. 2001;90(6):702-12. doi:10.1002/jps.1026.

82. Shibukawa A, Ishizawa N, Kimura T, Sakamoto Y, Ogita K, Matsuo Y, et al. Plasma protein binding study of oxybutynin by high-performance frontal analysis. J Chromatogr B Anal Technol Biomed Life Sci. 2002;768(1):177-88.

83. Sathyan G, Dmochowski RR, Appell RA, Guo C, Gupta SK. Effect of antacid on the pharmacokinetics of extended-release formulations of tolterodine and oxybutynin. Clin Pharmacokinet. 2004;43(14):1059-68. doi:10.2165/00003088-200443140-00008.

84. U.S. Food and Drug Administration. Ditropan XL® product label. http://www.accessdata.fda.gov/drugsatfda_docs/label/2003/ 17577se8-033,18211se8-016,20897slr010_ditropan_lbl.pdf: U.S. Food and Drug Administration,; 2015 [cited 2015 06/01/2015]; Available from: http://www.accessdata.fda.gov/drugsatfda_docs/label/2003/17577se8-033,18211se8-016,20897slr010_ditropan_lbl.pdf.

85. Conley R, Gupta SK, Sathyan G. Clinical spectrum of the osmotic-controlled release oral delivery system (OROS), an advanced oral delivery form. Curr Med Res Opin. 2006;22(10):1879-92. doi:10.1185/030079906X132613.

86. Hallifax D, Houston JB. Evaluation of hepatic clearance prediction using in vitro data: emphasis on fraction unbound in plasma and drug ionisation using a database of 107 drugs. J Pharm Sci. 2012;101(8):2645-52. doi:10.1002/jps.23202.
87. Foster JA, Houston JB, Hallifax D. Comparison of intrinsic clearances in human liver microsomes and suspended hepatocytes from the same donor livers: clearance-dependent relationship and implications for prediction of in vivo clearance. Xenobiotica. 2011;41(2):124-36. doi:10.3109/00498254.2010.530700.

88. Taketani M, Shii M, Ohura K, Ninomiya S, Imai $T$. Carboxylesterase in the liver and small intestine of experimental animals and human. Life Sci. 2007;81(11):924-32. doi:10.1016/ j.lfs.2007.07.026.

89. Sato Y, Miyashita A, Iwatsubo T, Usui T. Conclusive identification of the oxybutynin-hydrolyzing enzyme in human liver. Drug Metab Dispos. 2012;40(5):902-6. doi:10.1124/dmd.111.043208.

90. Rodgers T, Leahy D, Rowland M. Tissue distribution of basic drugs: accounting for enantiomeric, compound and regional differences amongst $\beta$-blocking drugs in rat. J Pharm Sci. 2005;94(6):1237-48. doi:10.1002/jps.20323.

91. Tsamandouras N, Rostami-Hodjegan A, Aarons L. Combining the 'bottom up' and 'top down' approaches in pharmacokinetic modelling: fitting PBPK models to observed clinical data. Br J Clin Pharmacol. 2015;79(1):48-55. doi:10.1111/ bcp.12234.

92. Varma MV, Obach RS, Rotter C, Miller HR, Chang G, Steyn SJ, et al. Physicochemical space for optimum oral bioavailability: contribution of human intestinal absorption and first-pass elimination. J Med Chem. 2010;53(3):1098-108. doi:10.1021/ jm901371v.

93. Sjögren E, Dahlgren D, Roos C, Lennernäs H. Human in vivo regional intestinal permeability: quantitation using site-specific drug absorption data. Mol Pharm. 2015. doi:10.1021/mp500834v. 